\title{
IS-T- -969
}

DE82 005448

A Survey of Organic Acid Eluents for Anion Chromatography

by

David Eugene Book

\section{MASTER}

M.S. Thesis submitted to Iowa State University

\author{
Ames Laboratory, U.S. DOE \\ Iowa State University \\ Ames, Iowa 50011
}

Date Transmitted: October 1981

PREPARED FOR THE U. S. DEPARTMENT OF ENERGY

UNDER CONTRACT NO. W-7405-Eng-82. 


\section{DISCLAIMER}

This report was prepared as an account of work sponsored by an agency of the United States Government. Neither the United States Government nor any agency Thereof, nor any of their employees, makes any warranty, express or implied, or assumes any legal liability or responsibility for the accuracy, completeness, or usefulness of any information, apparatus, product, or process disclosed, or represents that its use would not infringe privately owned rights. Reference herein to any specific commercial product, process, or service by trade name, trademark, manufacturer, or otherwise does not necessarily constitute or imply its endorsement, recommendation, or favoring by the United States Government or any agency thereof. The views and opinions of authors expressed herein do not necessarily state or reflect those of the United States Government or any agency thereof. 


\section{DISCLAIMER}

Portions of this document may be illegible in electronic image products. Images are produced from the best available original document. 


\section{DISCLAIMER}

This book was prepared as an account of work sponsored by an agency of the United States Government. Neither the United States Government nor any agency thereof, nor any of the ir employees, makes any warranty, express or implied, or assumes any legal liability or responsibility for the accuracy, completeness or usefulness of any information, apparatus, product, or process disclosed, or represents that its use would not infringe privately owned rights. Reference herein to any specific commercial product, process, or service by trade name, trademark, manufacturer, or oiherwise, does not necessarily constitute or imply its endorsement, recommendation, or favoring by the United States Government or any agency thereof. The views and opinions of authors expressed herein do not necessarily state or reflect those of the United States Government or any agency thereof.

Printed in the United States of America

Available from

National Technical information Semice

U.S. Department of Commerce

5265 Port Royal Road

Springfield, VA 22161 


\section{A survey of organic acid eluents for anion chromatography}

by

David Eugene Book

Department: Chemistry

Major: Analytical Chemistry

Approved:

In Charge of Major Work

For the Major Department

For the Graduate Cn71ege

Iowa State University

Ames, Iowa

1981 
TABLE OF CONTENTS

Page

INTRODUCTION

EXPERIMENTAL - . 5

Components and Modifications of the Dionex Model 10 Ion Chromatograph

Preparation and Specifications of the Anion-exchange Columns

Preparation of the Eluents 9

Preparation and Handing of the Samples 12

$\begin{array}{ll}\text { RESULTS AND DISCUSSION } & 14\end{array}$

Survey of Eluents $\quad 14$

Benzoic and nitrobenzoic acids 14

Phthalic acids I9

1,3,5-Benzenetricarboxylic and citric acids $\quad 24$

Nitrophenols 26

Sulfonic acids $\quad 32$

Phosphonic and phosphinic acids 35

Additional Data on 1,3,5-Benzenetricarboxylic Acid 37

Chromatographic conditions. 37

The eluent peak $\quad 38$

Inorganic anions $\quad 47$

Carboxylic acids $\quad 47$

Sulfonic acids 51 
CONCLUSIONS - 59

Choosing an Eluent 59

Eluents for Typical Separations 61

Separation of halide ions 61

Separation of chloride and sulfate. 61

Separation of multivalent inorganic anions. 62

Separation of small alkyl acids 62

Separation of aromatic acids 62

FUTURE WORK

REFERENCES $\quad \cdots \ldots 5$

APPENDIX 66 


\section{INTRODUCTION}

Ion exchange is the process of replacing one ion with a second ion. This process is usually carried out in water solution on a specially functionalized polystyrene resin. The actual replacement reaction involved in ion exchange is given in Equation 1.

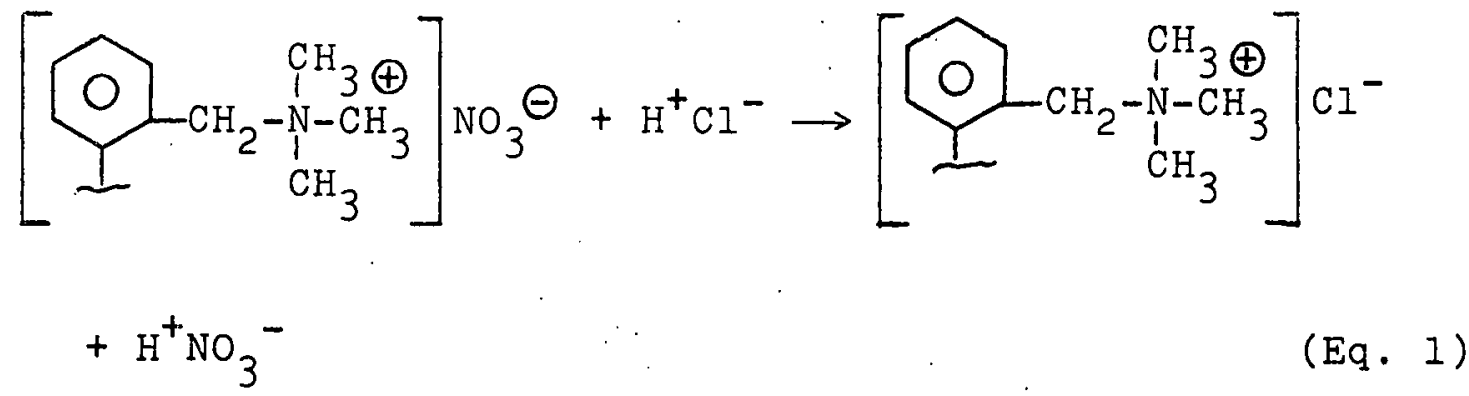

The use of ion exchange as a practical analytical tool depends on a number of things. The ion exchange must be performed in a chromatographic system with an efficient 1onexchange resin. A sensitive and universal detector must be used. An efficient eluent which is compatible with the other requirements of the system is needed. Finally, an eluent pump is necessary to allow the system to be automated and to speed up the separation of the ions.

An automated ion-exchange system which meets these requirements was introduced by Small, Stevens and Bauman in 1975 [1]. The unique features of their system were the combination of a conductivity detector with a method of 
lowering the eluent conductivity, which produced very good sensitivities for ionic samples. The system is capable of performing either anion exchange or cation exchange, but only the anion-exchange system will be discussed.

The anion-exchange system consists of a low capacity anion-exchange resin, which separates the anions, followed by a high capacity cation-exchange, suppressor column in the $\mathrm{H}^{+}$ form. The purpose of the cation column is to convert the eluent, which is always a dilute solution of a weak acid, from the ionic form to the protonated acid form. This conversion is necessary because a conductivity detector responds to all of the ions in solution and the unprotonated eluent would give too high a background conductance to allow this type of a detector to be used. The eluents used in this system were originally mixtures of $0.035-0.045 \mathrm{~F}$ sodium hydroxide and 0.005-0.015 F sodium phenate or 0.005-0.015 F solutions of sodium phenate alone. The currently recommended eluent [2] is a mixture of $0.003 \mathrm{M} \mathrm{NaHCO}_{3}$ and 0.0012-0.0036 $\mathrm{M}$ $\mathrm{Na}_{2} \mathrm{CO}_{3}$. This entire system is now commercially marketed by the Dionex Corporation as the Ion Chromatograph.

Gjerde, Fritz and Schmuckler [3] introduced a second method for performing ion chromatography which does not use a suppressor column. This system uses very low capacity ionexchange resins and lower concentrations of the eluent to maintain an eluent conductance which is low enough to permit. 
the use of a conductivity detector. Because of these constraints, the eluent used in this system must have a higher affinity for the resin and a lower equivalent conductance than the eluent used in the Dionex system. The eluents used in the nonsuppressed system typically consist of 0.00005 to $0.0005 \mathrm{M}$ solutions of potassium benzoate, benzoic acid, potassium phthalate, or ammonium sulfobenzoate.

Most of the components of nonsuppressed ion chromatography have received extensive attention. Methods for preparing very low capacity ion-exchange resins have been worked out $[4,5]$. The effect of variations in the exchange capacity of resins has been studied [5]. Separations of a wide variety of anion and cation samples have been achieved $[6,7]$. An extensive study on the properties of potential eluents, however, had not been performed when this study was initiated.

The purpose of this study is to survey a number of organic acids which have potential as eluents for anionexchange chromatography and to determine how the structure and properties of these acids affect their performance as eluents. A number of parameters will be evaluated for their effect on the performance of the eluent. These include the number, type, and structure of the acid groups, the overal structure of the molecule, and the electrical nature of the 
molecule, as reflected by its acid dissoclation constant. The effects of nonacid groups will also be evaluated. When the survey and evaluation of the eluents has been completed, a number of actual separations will be performed to demonstrate the potential uses of some of the eluents. A method for choosing an appropriate eluent for a specific type of separation will also be outlined. 


\section{EXPERIMENTAL}

Components and Modifications of the Dionex Model 10 Ion Chromatograph

All of the results were obtained using a modified version of a Dionex System Ten Ion Chromatograph. This system was modified to eliminate the need for a suppressor column and to reduce the number of pneumatic valves used. Since only one column was used the pump and regenerant tank associated with the suppressor column were eliminated (see Figure 1). In order to reduce the number of valves in the system, two modifications were made. The first was to connect the solvent delivery pump directly to a 2-liter eluent container using $2.5 \mathrm{~mm}$ Teflon tubing. The second modification consisted of running the eluent and sample directly into the detector after it came out of the separator column. This eliminated the suppressor valve (see Figure 2 for the modified system).

The other components of this system consisted of a pump, an injection system, a separator column and a conductivity detector. The pump was a Milton Roy model 396 Simplex constant-volume pump. The injection system consisted of a pair of four-way valves, arranged so that a $100 \mu l$ sample could be loaded into a $20.5 \mathrm{~cm}$ piece of tubing and then injected onto the top of the column. The glass analytical 


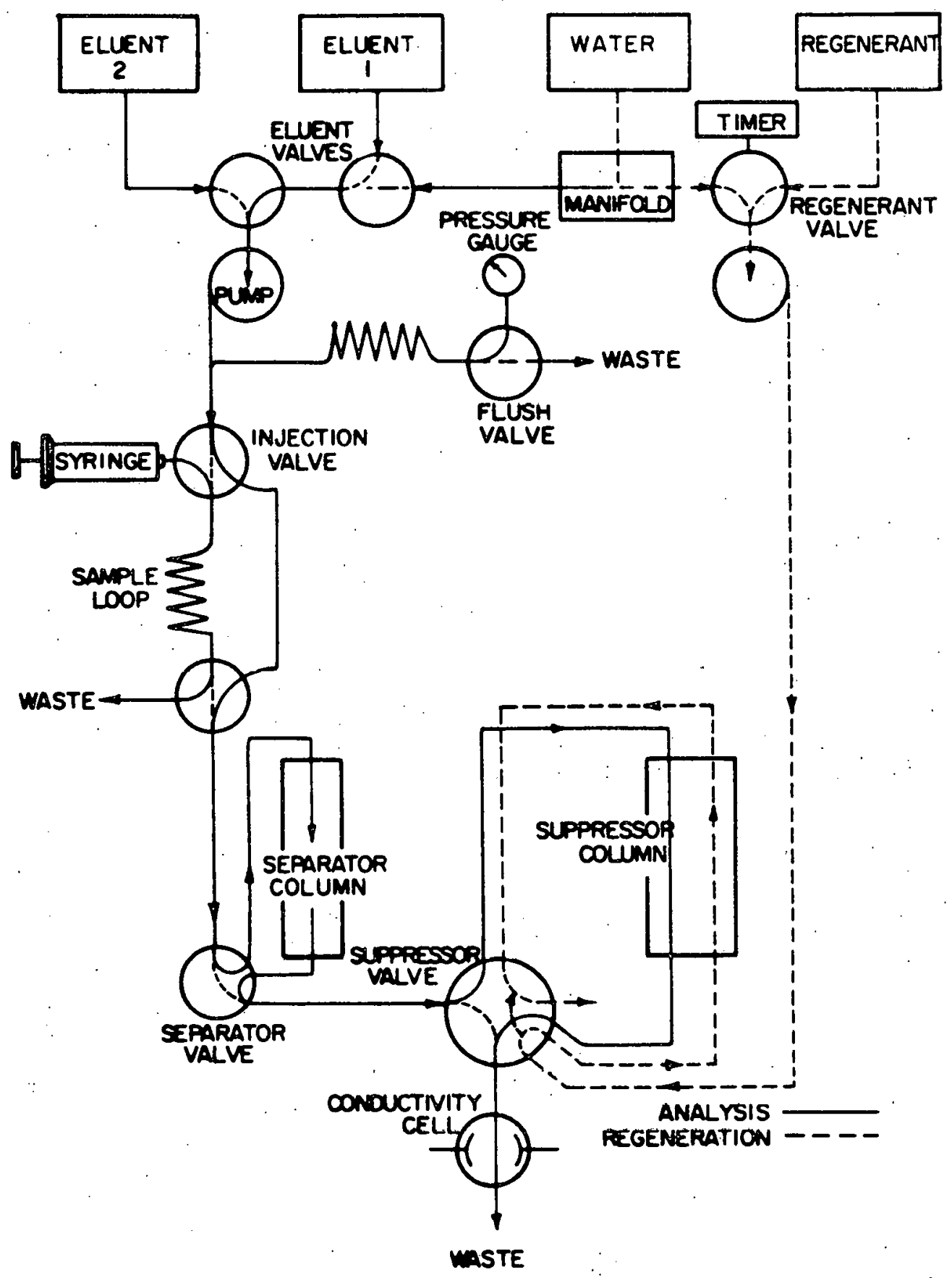

Figure 1. The Dionex Model 10 Ion Chromatograph 


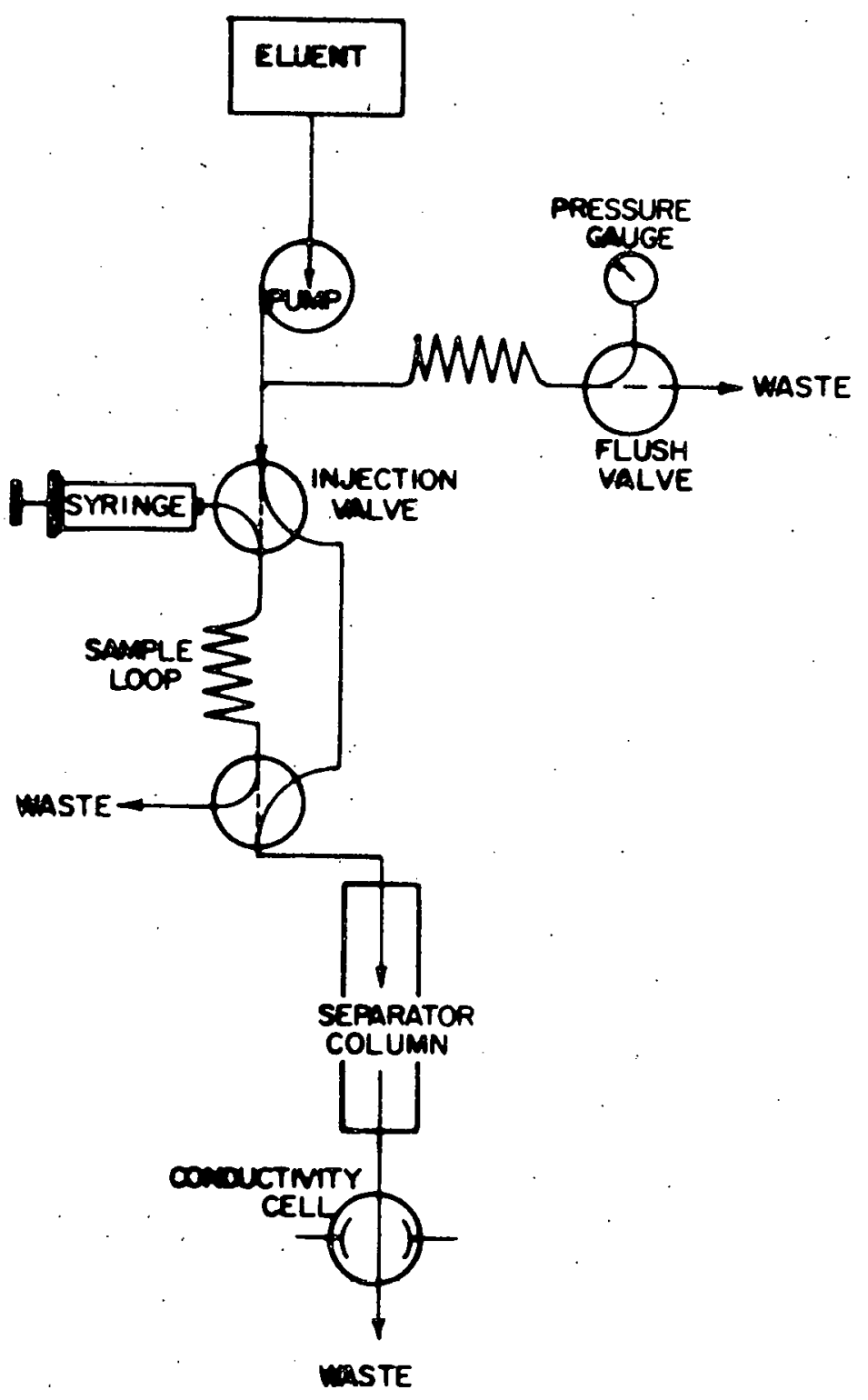

Figure 2. The Dionex Model 10 Ion Chromatograph after modification 
columns were prepared in this group. Their exact dimensions and preparation will be given later. The detector used was the one supplied with the model ten system. It has a cell volume of approximately $6 \mu \mathrm{l}$ with stainless steel electrodes. The conductivity meter has a range of $0-1000$ umhos and an offset switch with this same range. The recorder was a Fischer Recordall series 5000.

\section{Preparation and Specifications of the Anion-exchange Columns}

The analytical columns used in these experlments were prepared by fusing hard glass tubing of the proper inside diameter to the pre-formed glass end pieces of Altex 200-17 connectors. After the black plastic connectors were pressed over the glass end caps, the columns were packed using the wet slurry method.

The ion-exchange resin used for packing an analytical column was wetted with methanol, slurried with water, and then drawn into a syringe. A Luer adapter was used to secure the syringe to the plastic column fitting. Before this time, the opposite end of the column was plugged with glass wool and a plastic fitting was attached so the plug would not be forced out the end of the column. The slurry was then manually pushed through the syringe and into the column. When the column was filled with resin, it was 
connected to the ion chromatograph and an eluent of interest was pumped through the column for about 2 hours. This conditioned the column and compacted any loose resin particles. At the end of this time, the column was disconnected and resin was added to fill the void caused by settling. This pumping and filling procedure was repeated until no more settling of the resin occurred.

Three separate analytical columns were used during these experiments. The first column was $50 \mathrm{~cm}$ long with a $3 \mathrm{~mm}$ inside diameter and was packed with 0.007 meq/g functionalized XAD-1. The second column was $50 \mathrm{~cm}$ long with a $4 \mathrm{~mm}$ inside diameter and was packed with $0.0057 \mathrm{meq} / \mathrm{g}$ functionalized. $X A D-1$ resin. The third column was $50 \mathrm{~cm}$ long with a $3 \mathrm{~mm}$ inside diameter and was packed with $0.016 \mathrm{meq} / \mathrm{g}$ AN59-XA. This last resin was prepared from ultra-clean XAD-1. which was carefully sized and functionalized by Robert Barron. All of the anion exchange resins were $250-325$ mesh.

\section{Preparation of the Eluents}

The preparation of the eluents required control both of the eluent concentration and $\mathrm{pH}$. A special dilution apparatus was designed to carry out this procedure efficiently. This apparatus consisted of a 2-liter conical flask which contained a magnetic stirring bar. The opening of the flask was sealed with a number 10 rubber stopper which 
had two holes bored through it. The larger hole was $1.5 \mathrm{~cm}$ in diameter and the smaller hole was $0.5 \mathrm{~cm}$ in diameter. A combination $\mathrm{pH}$ electrode was pushed through the larger hole and was used to measure the $\mathrm{pH}$ of the solution in the flask. A disposable Pasteur pipette with a small rubber bulb was placed in the smaller hole. This pipette contained approximately $0.1 \mathrm{M} \mathrm{KOH}$ and was used to adjust the $\mathrm{pH}$ of the solution. The pipette was easily removed and refilled if additional base. was needed to reach the desired $\mathrm{pH}$. The complete apparatus is shown in Figure. 3 .

An eluent was prepared by calculating the amount of reagent needed to produce $2 l$ of eluent of the desired concentration: This amount of reagent was weighed out and placed in the dilution apparatus along with about $1.7 \ell$ of deionized water. The magnetic stirrer was turned on and the $\mathrm{pH}$ was monitored continuously. Dilute $\mathrm{KOH}$ was added dropwise from the Pasteur pipette until the proper $\mathrm{pH}$ was reached. The solution was then quantitatively transferred into a $2 \ell$ volumetric flask and diluted to volume. The eluent was thoroughly mixed in the volumetric flask and transferred to a 2 \& Nalgene bottle, which was used as the eluent reservoir for the ion chromatograph. The $\mathrm{pH}$ was rechecked and adjusted by adding a few drops of $\mathrm{KOH}$ if necessary.

The procedure outlined above was used to prepare all, of the eluents used in the eluent survey. The eluents used in 


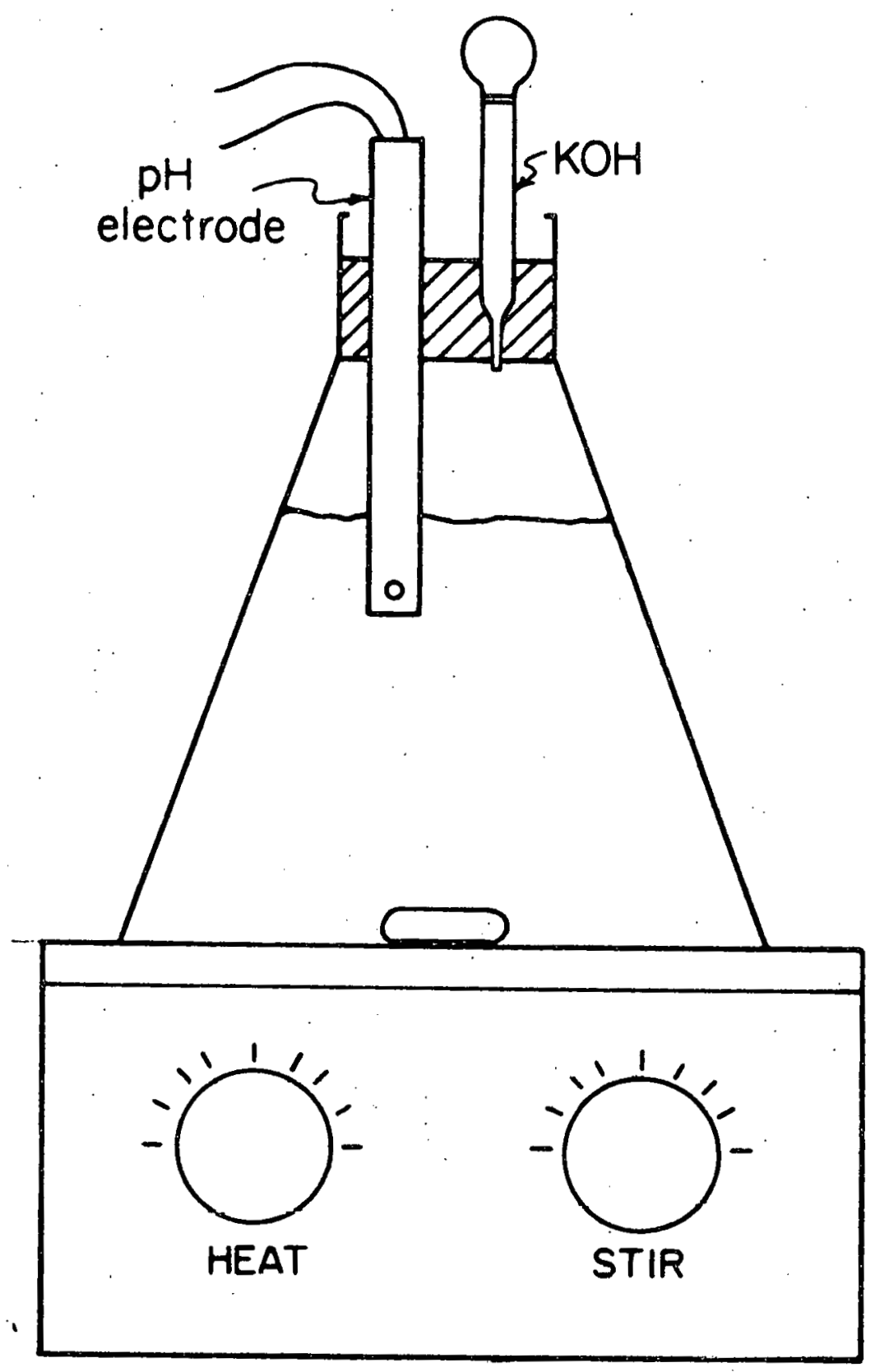

Figure 3. The dilution apparatus used for preparing eluents 
the pH study were prepared in a similar manner, except that a $0.01 \mathrm{M}$ solution of $1,3,5$-benzenetricarboxylic acid was prepared and the amount of this solution necessary to produce the desired eluent concentration was pipetted into the dilution apparatus.

Preparation and Handling of the Samples

All of the samples used in these experiments were prepared from the highest purity reagents available in this laboratory and no further purification was attempted. The inorganic samples were prepared from either the potassium or sodium salt of the anion of interest. The organic samples were prepared either from the free acid or the sodium, potassium or ammonium salt.

The samples were prepared by dissolving a known amount of the compound containing the anion of interest in $500 \mathrm{ml}$ of deionized water. The samples were then transferred to $500 \mathrm{ml}$ Nalgene bottles for storage. All of the samples are stable indefinitely if kept tightly sealed, except for solutions of sulfite or nitrite. Because both sulfite and nitrite are easily oxidized in solution, samples containing these anions were always prepared just before they were analyzed. In all cases the concentration of the samples was reported as ppm of the free anion. 
The retention time of a particular ion was determined by pouring $10 \mathrm{ml}$ of the sample containing that ion into a clean beaker. A 3-ml syringe was rinsed with two portions of deionized water and then rinsed with the sample in order to avoid contamination. The syringe was refilled with the sample and the solution was injected into the Ion Chromatograph. A strip-chart recording of the elution was begun and the retention time for the anion was determined from the position of its peak on this chromatogram.

The procedure for the injection of the sample consisted of a number of steps. First, the sample injection switch was put in the load position and $3 \mathrm{ml}$ of sample were pushed through the syringe and into the Ion Chromatograph. This step rinsed the $100 \mu \mathrm{I}$ sample loop and filled it with the sample. Next, the injection switch was moved to the load position and the beginning of the chromatogram was marked simultaneously on the strip chart. When the injection switch was moved to the inject position, the eluent was forced through the sample loop, pushing the sample onto the top of the ion-exchange column and beginning elution of the sample down the column. After about 25 seconds, the sample injection switch was moved back to the load position so it would be ready for the next injection. The elution of the sample was not disturbed because the eluent also flowed through the ion-exchange column in the load position. 


\section{RESULTS AND DISCUSSION}

Survey of Eluents

Benzoic and nitrobenzoic acids

A study to determine the effect an electron-withdrawing substituent has on the eluent properties of benzoic acid was carried out. The eluents were $1 \times 10^{-4} \mathrm{M}$ solutions of benzoic, o-nitrobenzoic, m-nitrobenzoic, and p-nitrobenzoic acids. The $\mathrm{pH}$ of these solutions was adjusted to $6.9,7.8$; 7.8 and 8.0 , respectively, to insure that each eluent was completely ionized. (See the Appendix for the $\mathrm{pk}_{\mathrm{a}}$ of all eluents.) All of the trials were run on the $0.007 \mathrm{meq} / \mathrm{g}$ XAD-1 anion-exchange column with an eluent flow rate of $1.5 \mathrm{ml} / \mathrm{min}$.

The results of the chromatographic trials are given in Table 1, and some typical separations are given in Figures 4 and 5. These results indicate that the efficiency of benzoic and nitrobenzoic acid eluents decreases in the following order: p-nitrobenzoic $\simeq$ m-nitrobenzoic > benzoic > onitrobenzoic.

The carboxylate anions of meta and para substituted nitrobenzoic acid are stronger eluents than potassium benzoate. The reason for this effect is the electronwithdrawing nature of the nitro $\left(-\mathrm{NO}_{2}\right)$ substituent. The nitro group pulls electrons away from the carboxylate 
Table 1. Benzoic and nitrobenzoic acids ${ }^{a}$

\begin{tabular}{|c|c|c|c|c|c|c|c|c|}
\hline \multirow[t]{2}{*}{ Sample } & \multicolumn{2}{|c|}{$\begin{array}{l}\text { p-nitrobenzoic } \\
\text { acid }\end{array}$} & \multicolumn{2}{|c|}{$\begin{array}{l}\text { m-nitrobenzoic } \\
\text { acid }\end{array}$} & \multirow{2}{*}{$\begin{array}{c}\text { benzoic } \\
\mathrm{T}_{\mathrm{R}}^{\prime} \\
(\min )\end{array}$} & \multirow{2}{*}{$\begin{array}{l}\text { acid } \\
W_{\frac{1}{2}} \\
(\min )\end{array}$} & \multicolumn{2}{|c|}{$\begin{array}{l}\text { o-nitrobenzoic } \\
\text { acid }\end{array}$} \\
\hline & $\begin{array}{c}\mathrm{T}_{\mathrm{R}}^{p} \\
\left(\mathrm{~min}_{\mathrm{i}}\right)\end{array}$ & $\begin{array}{l}W_{\frac{1}{2}} \\
(\min )\end{array}$ & $\begin{array}{c}\mathrm{T}_{\mathrm{R}}^{\prime} \\
(\mathrm{min})\end{array}$ & $\begin{array}{l}W_{\frac{3}{2}} \\
(\mathrm{~min})\end{array}$ & & & $\begin{array}{c}\mathrm{T}_{\mathrm{R}}^{\prime} \\
(\mathrm{min})\end{array}$ & $\begin{array}{c}W_{\frac{1}{2}} \\
(m i n)\end{array}$ \\
\hline $9.6 \mathrm{ppm} \mathrm{Cl}{ }^{-}$ & 3.05 & 1.40 & 3.70 & 1.60 & 5.70 & 1.30 & 7.65 & .2 .50 \\
\hline $0.96 \mathrm{ppm} \mathrm{Cl}^{-}$ & 3.05 & 0.60 & 3.70 & 0.80 & 5.70 & 0.70 & 7.65 & 1.50 \\
\hline $9.8 \mathrm{ppm} \mathrm{Br}-$ & 4.60 & 0.90 & 4.85 & 1.20 & 6.85 & 1.05 & 9.85 & 1.60 \\
\hline $9.1 \mathrm{ppm} \mathrm{NO}_{3}^{-}$ & 4.90 & C. 90 & 5.05 & 1.30 & $7.20^{\circ}$ & 1.05 & 10.55 & 1.70 \\
\hline $24.7 \mathrm{ppm} \mathrm{I}^{-}$ & 10.40 & 2.00 & 10.45 & 1.40 & 17.80 & 3.30 & 20.40 & 2.70 \\
\hline
\end{tabular}

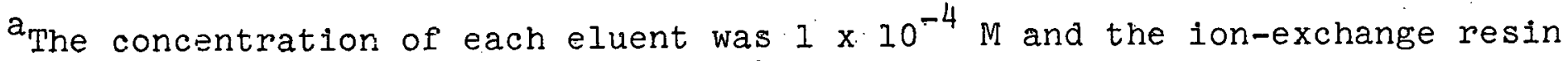
was 0.007 meq/g XAD-1 for all of the trials. 


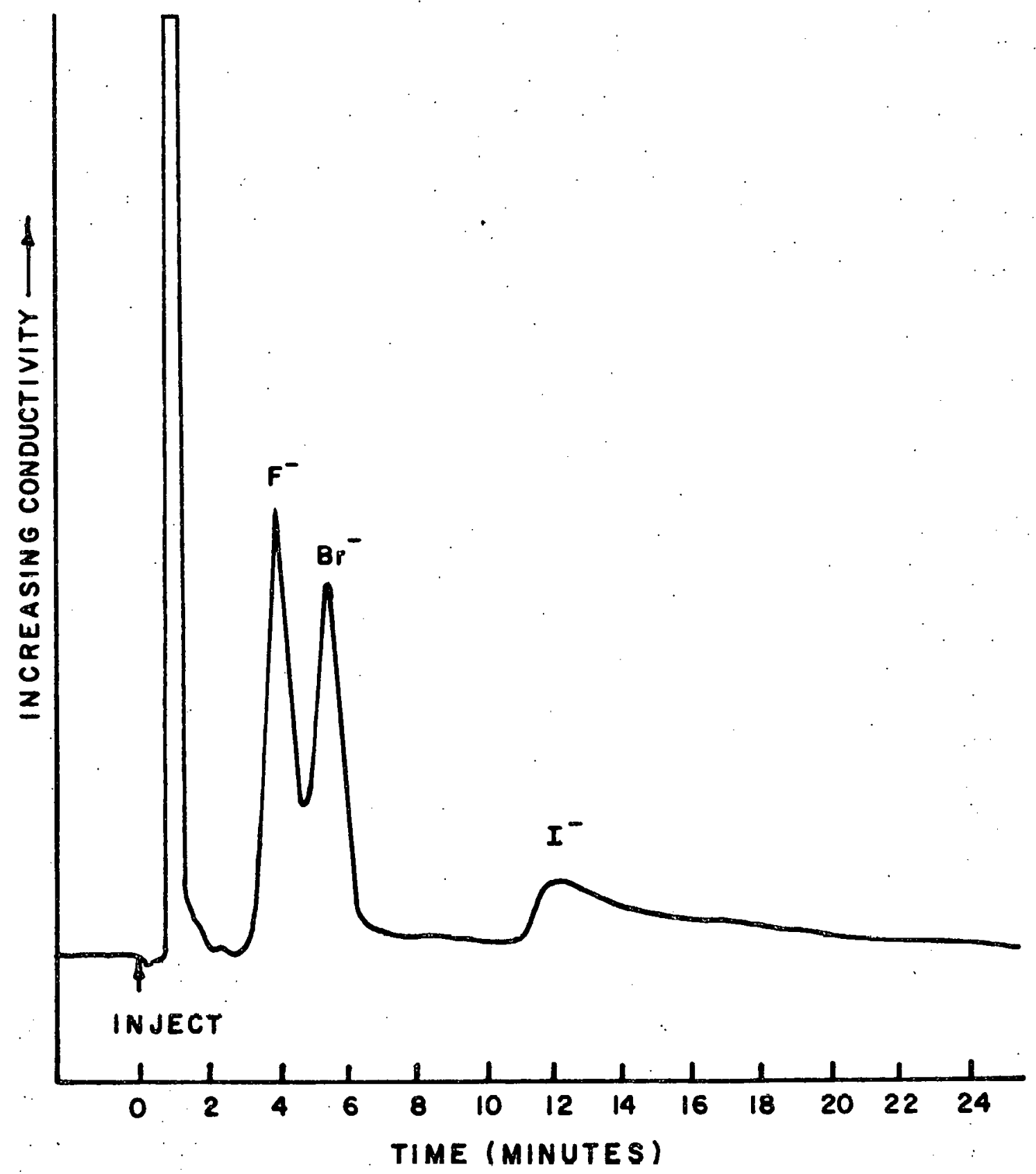

The eluent was $1 \times 10^{-4} \mathrm{M}$ benzolc acid at a $\mathrm{pH}$ of 7.2 . The anion-exchange column was $0.016 \mathrm{meq} / \mathrm{g}$ AN59-XA. The sample was. $3.94 \mathrm{ppm}$ fluoride, $2.60 \mathrm{ppm}$ bromide and $7.40 \mathrm{ppm}$ iodide.

Figure 4. Separation of fluoride, bromide, and iodide using benzoic acid 


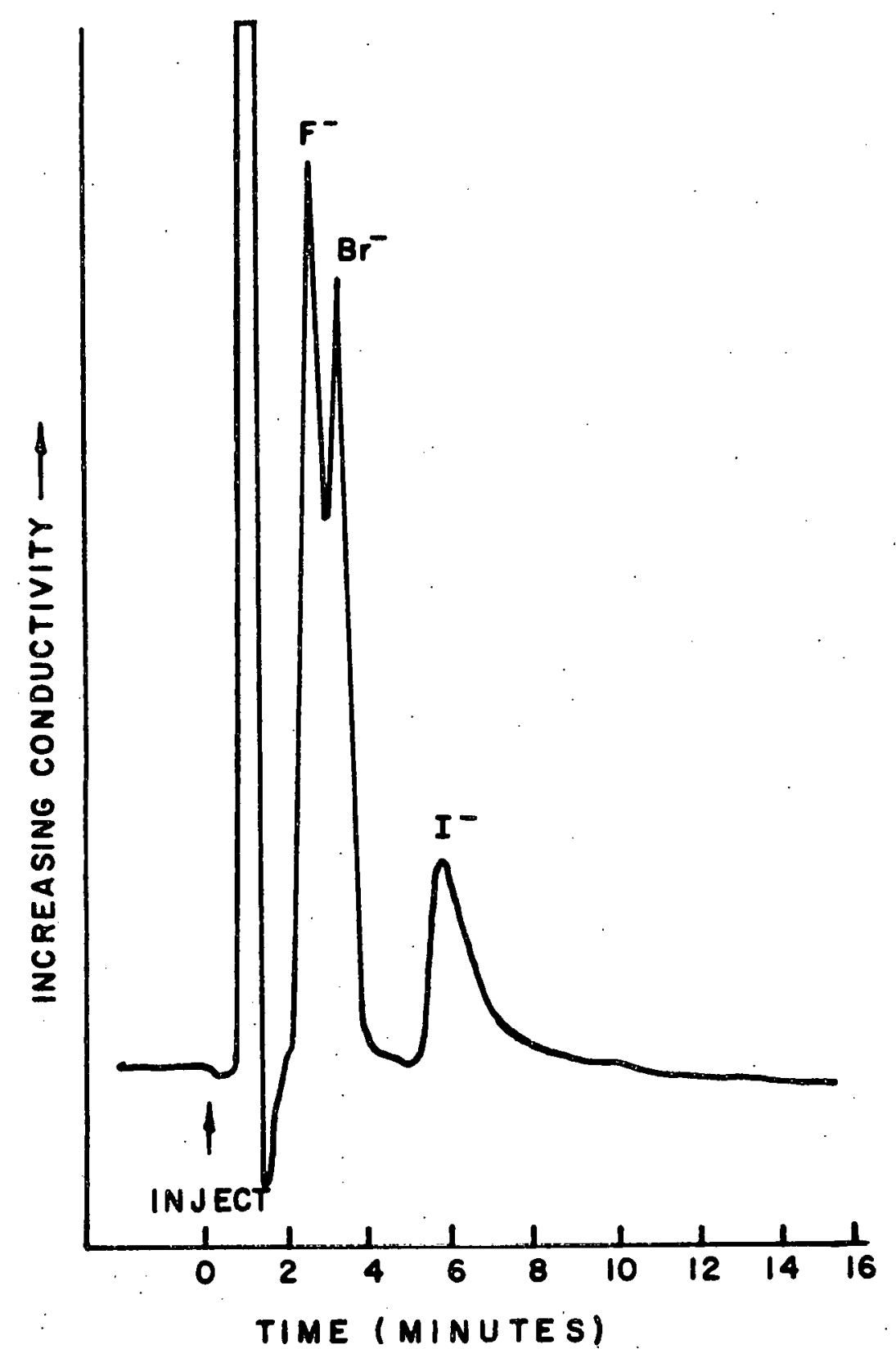

The eluent was $1 \times 10^{-4} \mathrm{M}$ p-nitrobenzoic acid at a $\mathrm{pH}$ of 7.2 . The anion-exchange column was $0.016 \mathrm{meq} / \mathrm{g}$ AN59-XA. The sample was $3.94 \mathrm{ppm}$ fluoride, $2.60 \mathrm{ppm}$ bromide, and $7.40 \mathrm{ppm}$ iodide.

Figure 5. Separation of fluoride, bromide, and iodide using n-nitronenzote asid 
portion of the anion and stabilizes the molecule by dispersing some of the charge through more of the nitrobenzoate anion. Because of this increased stability, a nitrobenzoate anion requires less solvation than a benzoate anion. This decreased solvation makes it easier for nitrobenzoate to interact with the ion-exchange sites on the resin and a larger portion of the collision between the nitrobenzoate anions and the exchange sites result in ion exchange. It is this increased exchange efficiency which makes the meta and para nitrobenzoic acids stronger eluents than benzoic acid.

The carboxylate anion of o-nitrobenzoic acid is a weaker eluent than potassium benzoate. The decrease in eluent strength of o-nitrobenzoate is due to a complex interaction between the nitro group and the carboxylate group, known as the ortho effect. This effect arises from the proximity of the two substituents on the benzene ring. The exact nature of the ortho effect is described by the modified Hammett equation given below.

$$
Q=a\left(s_{i}\right)+b\left(s_{r}\right)+c\left(r_{v}\right)+h .
$$

$Q$ - the ovcrall cffect of the substituent (a change in free energy)

$s_{i}=$ localized electrical effect

$s_{r}=$ resonance electrical effect

$r_{v}=$ steric effect 
$\mathrm{h}=$ constant

$a=$ scale factor

$\mathrm{b}=$ scale factor

$c=$ scale factor

A comprehensive study of the ortho effect by $M$. Charton [8]. was consulted to determine whether the steric factor or the electrical factors in the equation above is more important. The study reviewed 265 sets of published data dealing with ortho substituents and concluded that the steric factor is not generally significant. Even for substituents as large as a nitro group, the only. significant factors are the electrical factors.

The ortho effect causes the charge on the carboxylate ion to be dispersed more effectively through the molecule for the ortho isomer of potassium benzoate than for the meta and para isomers. Because of this additional diffusion of charge, the o-nitrobenzoate ion is not strongly held by the positively charged ion-exchange sites on the resin. It is this decrease in the electrostatic attraction between the resin and eluent which causes o-nitrobenzoic acid to be a weaker eluent than the other benzoic eluents in this study.

\section{Flithalie acida}

A study was performed to determine what effect the relative positions of the acid groups have on the eluent. properties of the phthalic acids. The elients were 
$1 \times 10^{-4} \mathrm{M}$ solutions of o-phthalic. isophthalic and terephthalic acids. The $\mathrm{pH}$ of these solutions was adjusted to $6.9,6.9$ and 6.8 , respectively, to insure that each eluent was completely ionized. All of the trials were run on the 0.007 meq/g XAD-I anion exchange column with an eluent flow rate of $1.5 \mathrm{ml} / \mathrm{min}$.

A separation of four anions using o-phthalic acid as the eluent is shown in Figure 6, and the results of all the chromatographic trials are given in Table 2. These results indicate that the efficiency of the isomeric phthalic acids decreases in the following order: isophthalic > o-phthalic > terephthalic.

The difference in the performance of the various phthalic acideluents is controlled by two factors. The first factor is the stability of the divalent anion which depends on the ability of the anion to disperse the excess electrical charge. The second factor is the geometric arrangement of the carboxylate groups around the benzene ring.

The stability of the divalent anion is proportional to the second ionization constant $\left(\mathrm{K}_{\mathrm{a} 2}\right)$ of the phthalic acid, with the smaller constant corresponding to the more stable anion. The results from the nitrobenzoic eluent study indicate that in the absence of other effects the more stable anion is the better eluent. If the stability of the anion 


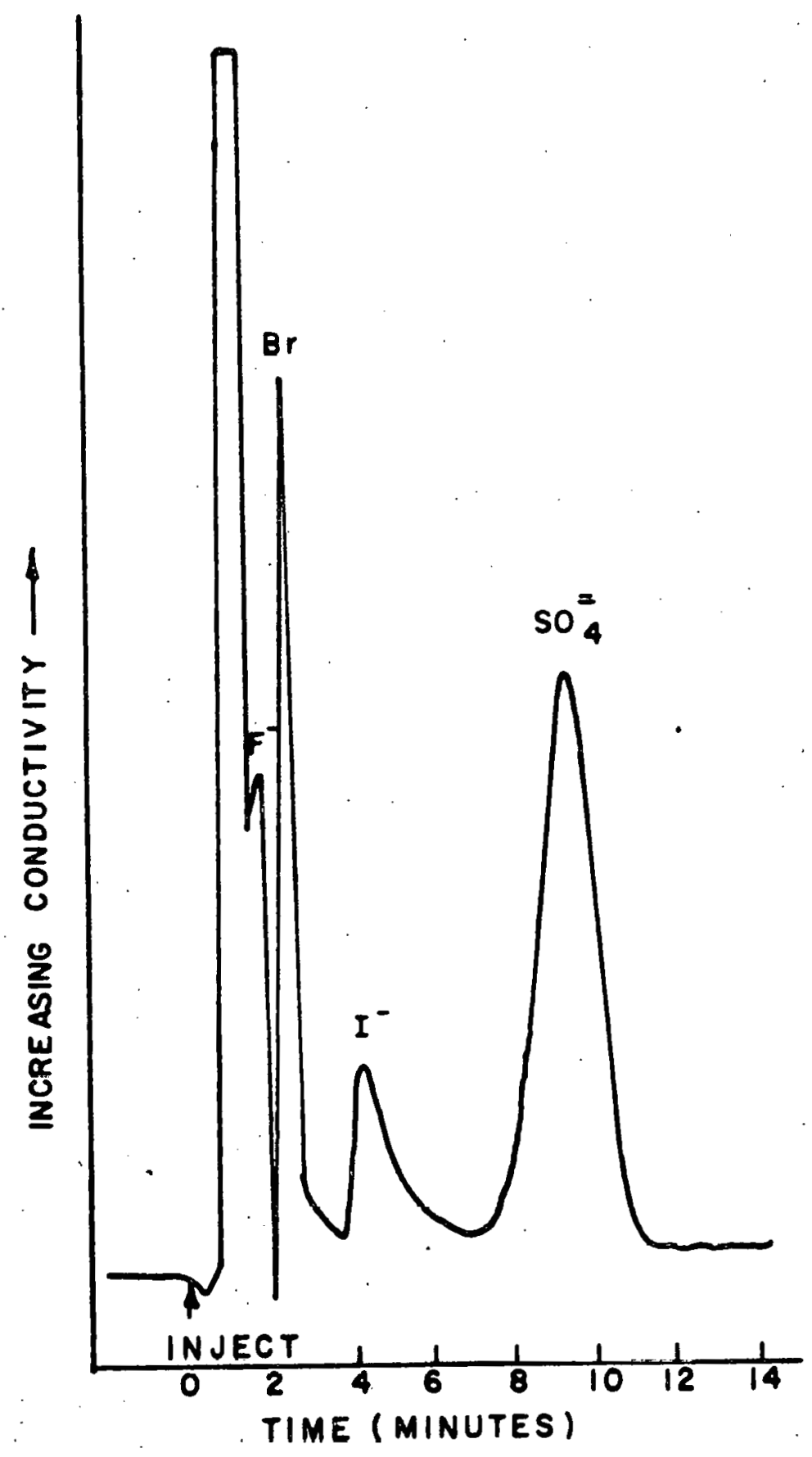

The eluent was $1 \times 10^{-4} \mathrm{M}$ o-phthalic acid at a pH of 7.4 . The anion-exchange column was $0.016 \mathrm{meq} / \mathrm{g}$ AN59-XA. The sample was $4.25 \mathrm{ppm}$ fluoride $6.0 \mathrm{ppm}$ bromide, $6.8 \mathrm{ppm}$ iodide, and $9.0 \mathrm{ppm}$ sulfate.

Figure 6. Separation of fluoride bromide, iodide, and sulfate using o-phthalic acid 
Table 2. Phthalic acids ${ }^{a}$

\begin{tabular}{|c|c|c|c|c|c|c|}
\hline \multirow[t]{2}{*}{ Sample } & \multicolumn{2}{|c|}{ isophthalic acid } & \multicolumn{2}{|c|}{ o-phthalic acid } & terephthalic & \multirow{2}{*}{$\begin{array}{l}\text { acid } \\
(\min )\end{array}$} \\
\hline & $\mathrm{T}_{\mathrm{R}}^{\prime}(\min )$ & $W_{\frac{1}{2}}(\min )$ & $\mathrm{T}_{\mathrm{R}}^{\prime}(\min )$ & $W_{\frac{1}{2}}(\min )$ & $\mathrm{T}_{\mathrm{R}}^{\prime}(\min )$ & \\
\hline $\mathrm{C} .96 \mathrm{ppm} \mathrm{Cl}-$ & $1.60^{\circ}$ & 0.25 & $1.70^{\mathrm{C}}$ & 0.30 & 2.00 & 0.25 \\
\hline $9.8 \mathrm{ppm} \mathrm{Br}$ & 1.95 & 0.40 & 2.10 & 0.40 & $2: 40$ & 0.40 \\
\hline 9.1. ppm $\mathrm{NO}_{3}^{-}$ & 1.95 & 0.40 & 2.20 & 0.40 & 2.65 & 0.40 \\
\hline $24.7 \mathrm{ppm} \mathrm{\textrm {I } ^ { - }}$ & 3.10 & 0.50 & 3.70 & 0.60 & 3.95 & 0.50 \\
\hline $27.6 \mathrm{ppm} \mathrm{SO}_{4}^{-2}$ & $7 \cdot 35$ & 1.20 & 8.50 & 1.30 & 10.45 & 1.40 \\
\hline $2.76 \mathrm{ppm} \mathrm{SO}_{4}^{-2}$ & 7.35 & 0.90 & 8.50 & 1.00 & 10.45 & 1.20 \\
\hline
\end{tabular}

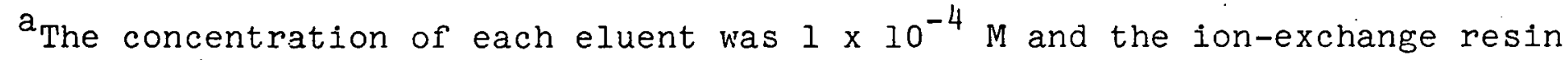
was $0.007 \mathrm{meq} / \mathrm{g} X A D-1$ for all of the trials.

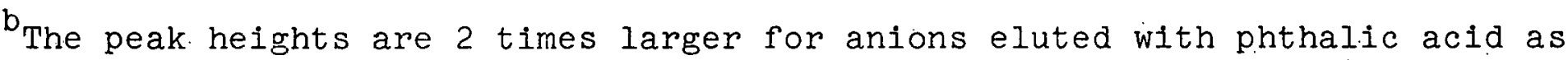
compared to the other eluents in this study.

${ }^{\mathrm{c}} \mathrm{Cl}^{-}$is not completely resolved from the pseudo peak. 
is the controlling factor, the eluent strength should decrease from terephthalic acid to isophthalic acid because the second $\mathrm{pK}_{\mathrm{a}}$ for these acids is 4.46 and 4.60 , respectively. Because of the electrical nature of the ortho effect, it is difficult to predict how phthalic acid $\left(\mathrm{pK}_{\mathrm{a} 2}=5.42\right)$ will behave.

The most favorable geometries are the ones with the carboxylate groups closest together. This arrangement increases the polarity of the phthalate anion, which enhances its attraction for the ion-exchange sites. It also improves the possibility that the carboxylate groups will work cooperatively once they are attached to an ion-exchange site. If the geometric arrangement is the controlling factor, phthalic and isophthalic acids should be better eluents than terephthalic acid.

The results of the experiments show that the geometry of the anion is the major factor, although electrical effects may be significant. Space-filling models of the phthalate and isophthalate ions show that both carboxylate groups could interact with a single ion-exchange site. Even if the two groups act independently, the proximity of the second carboxylate group enhances the probability that the phthalate ion will reattach itself to the same ion-exchange site after a potential ion-exchange collision occurs. 
No cooperative actions can occur with terephthalic acid because the carboxylate groups are on opposite sldes of the benzene ring. The large distance between these groups also reduces the likelihood of reattachment to an ion-exchange site. These steric factors enhance the eluent strength of both phthalic and isophthalic acid but do not improve the eluent strength of terephthalic acid.

\section{1,3,5-Benzenetricarboxylic and citric acids}

A study was performed to evaluate the eluent properties of organic compounds which contain three carboxylic acid groups. The eluents were $1.25 \times 10^{-4}$. M solutions of citric and i,3,5-benzenetricarboxylic acid. The latter compound will be referred to by its common name, trimesic acid. The $\mathrm{pH}$ of both solutions was adjusted to 8.0. All of the trials were run on the $0.016 \mathrm{meq} / \mathrm{g}$ AN59-XA anion exchange column with an eluent flow rate of $1.6 \mathrm{ml} / \mathrm{min}$.

The results of the chromatographic trials are given in Table 3. These results indicate that both acids are very strong eluents and that their eluent strength decreases in the following order: trimesic acld > citric acid.

Although trimesic and citric acids both contain the same number of carboxylic acid groups, they are very different compounds. Trimesic acid contains three acld groups arranged symmetrically around a benzene ring, while citric acid is aliphatic and contains an $\mathrm{OH}$ group in addition to the acid 
Table 3. 1,3,5-Benzenetricarboxylic and citric acids

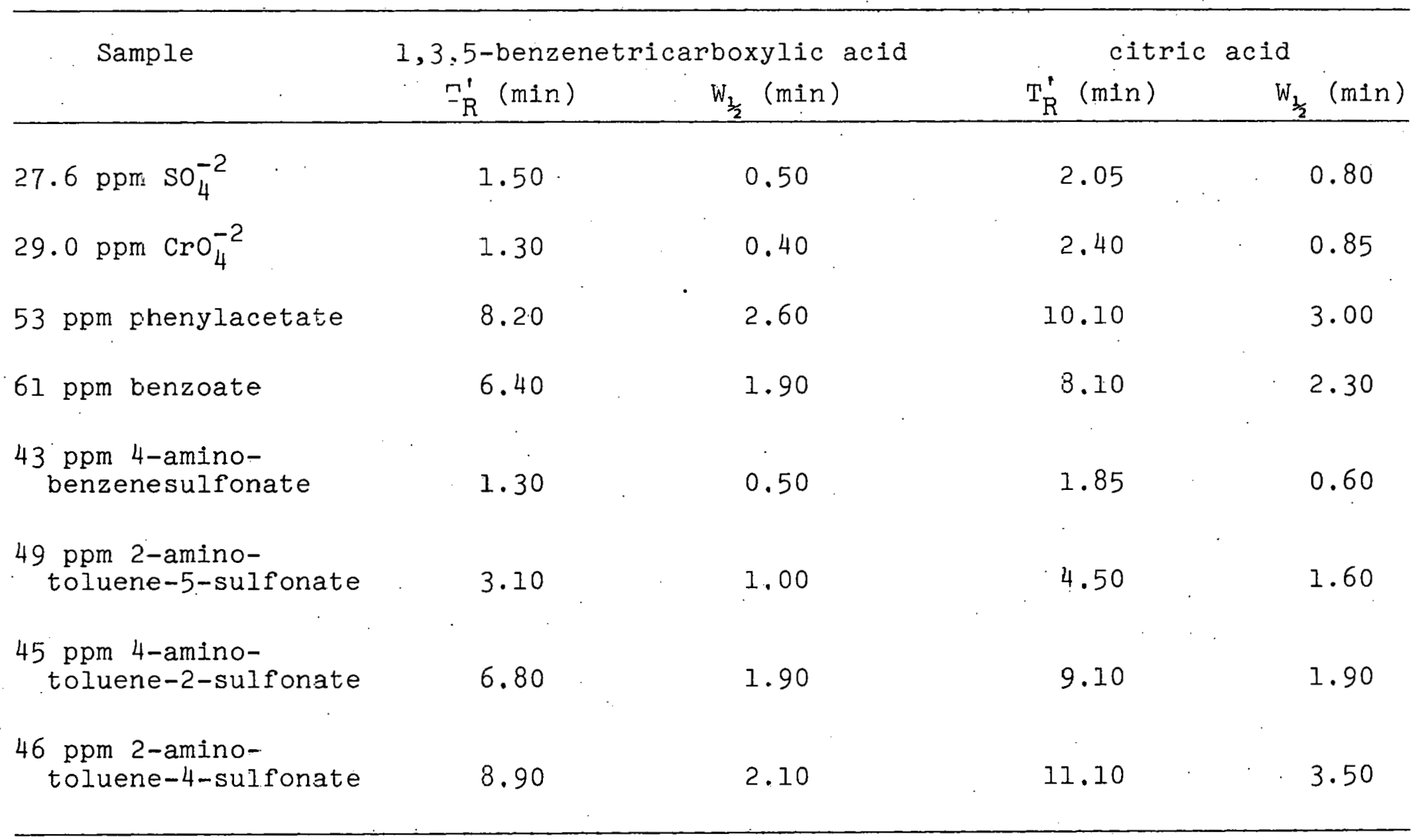

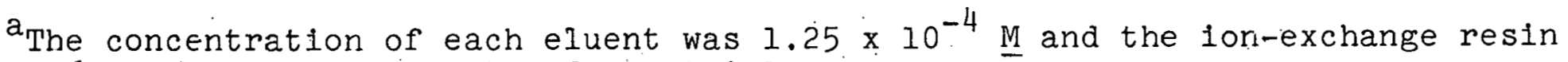
was $0.06 \mathrm{meq} / \mathrm{g}$ AN59-XA for all of the trials. 
groups. Trimesic acid $\left(\mathrm{pK}_{\mathrm{a} 3}=4.70\right)$ is also a stronger acid than citric acid $\left(\mathrm{pK}_{\mathrm{a} 3}=6.39\right)$.

It is these differences which cause trimesic acid to be a stronger eluent than citric acid. For reasons which were discussed previously, the stronger acid is generally the stronger eluent. The aromatic nature of trimesic acid may also enhance its eluent strength because aromatic molecules have a higher affinity than aliphatic molecules for XAD-I. Although this last factor is very important for most of the eluents studied, it may be only marginally important for these particular eluents since the attraction to XAD-1 decreases as the molecules become more ionic.

The difference in the structure of the two molecules also allows the eluents to have different selectivities for various anions. The data in Table 3 indicate that chromate elutes before sulfate when trimesic acid is used as the eluent, but it elutes after sulfate when citric acid is the eluent. 'These types of' selectivity difterences can be very important when performing difficult separations and both citric and trimesic acids should be evaluated when choosing an eluent for the separation of multivalent anions.

\section{Nitropheno1s}

A study of the eluent properties of compounds containing a phenolic OH group was undertaken to determine if they could 
be used as alternatives to carboxylic acid eluents. The eluents in this study were $1 \times 10^{-4}$ M solutions of o-nitrophenol, m-nitrophenol, p-nitrophenol, and dihydroxyp-benzoquinone. The $\mathrm{pH}$ of these solutions was adjusted to $8.6,9.0,8.6$ and 7.9 , respectively. All of the trials were run on the $0.0057 \mathrm{meq} / \mathrm{g}$ XAD-1 column with a pumping rate of $1.5 \mathrm{ml} / \mathrm{min}$.

Because of the high pH of these eluents, the $\mathrm{CO}_{2}$ dissolved in the sample solutions became a problem. The $\mathrm{CO}_{2}$ was converted to bicarbonate ions in the basic eluents and this additional ion interfered with the determination of some samples. Bromide, nitrate and bicarbonate were especially easy to mistake for each other, and special care was used to determine which peak was caused by bicarbonate and which peak was caused by the sample ion. The identification was accomplished by injecting a second sample which had a higher concentration of the ion of interest. The peak caused by the sample became larger, while the bicarbonate peak remained the same size.

The entire problem of bicarbonate interference can be avoided by either degassing all of the solutions or decreasing the $\mathrm{pH}$ of the eluent. Neither approach was used extensively due to the survey nature of the study. Degassing the solutions by bubbling He through them is inconvenient and time-consuming if a variety of samples and eluents are used. 
Changing the $\mathrm{pH}$ would have changed the extent to which the eluents were ionized and would have made it very difficult to compare phenols to other types of eluents.

The results of the chromatographic trials are given in Table 4 and a separation using o-nitrophenol as the eluent is shown in Figure 7 . These results indicate that the efficiency of the nitrophenol and dihydroxybenzoquinone eluents decreases in the following order: 2,5-dihydroxy-pbenzoquinone > o-nitrophenol > m-nitrophenol > p-nitrophenol.

Dihydroxy-p-benzoquinone is a stronger eluent than any of the nitrophenols. This is expected because it forms a divalent anion while the nitrophenols form monovalent anions. The eluent strength of 2,5-dihydroxy-p-benzoquinone is approximately the same as that of phthalic acid.

The $\mathrm{pK}_{\mathrm{a}}$ values of the ortho, meta and para isomers of nitrophenol are $7.2,8.4$, and 7.1. Because of the similarity of the value of the $\mathrm{pK}_{\mathrm{a}}$ for the ortho and para isomers, the contribution to eluent strength caused by the stability of the anion should be minimized. This allows the eluent strength of these two isomers to be compared solely on the contributions from steric factors. Using only steric factor factors, o-nitrophenol should be a stronger eluent than p-nitrophenol.

Both steric and stability factors influence the eluent strength of m-nitrophenol. These factors should cause the 
Table 4. Nitrophenols and dihydroxybenoquinone ${ }^{a}$

\begin{tabular}{|c|c|c|c|c|c|c|c|c|}
\hline \multirow[t]{2}{*}{ Sample } & \multicolumn{2}{|c|}{ o-nitrophenol } & \multicolumn{2}{|c|}{ m-nitrophenol } & \multicolumn{2}{|c|}{ p-nitrophencl } & \multicolumn{2}{|c|}{ dihydroxy-p-benzoquinone } \\
\hline & $\begin{array}{c}\mathrm{T}_{\mathrm{R}}^{\prime} \\
(\mathrm{min})\end{array}$ & $\begin{array}{l}\mathrm{w}_{\frac{1}{2}} \\
(\min )\end{array}$ & $\begin{array}{c}\mathrm{T}_{\mathrm{R}}^{\prime} \\
(\mathrm{min})\end{array}$ & $\begin{array}{c}W_{\frac{1}{2}} \\
(\min )\end{array}$ & $\begin{array}{c}\mathrm{T}_{\mathrm{R}}^{\prime} \\
(\min )\end{array}$ & $\mathrm{W}_{\frac{1 / 2}{2}}$ & $\begin{array}{c}\mathrm{T}_{\mathrm{R}}^{\prime} \\
(\min )\end{array}$ & $\begin{array}{l}W_{\frac{1}{2}} \\
(\min )\end{array}$ \\
\hline $10.3 \mathrm{ppm} \mathrm{Cl}^{-}$ & 2.10 & 0.90 & 2.50 & 0.70 & 3.80 & 1.40 & 1.80 & 0.70 \\
\hline $13.0 \mathrm{ppm} \mathrm{Br}-$ & 2.35 & 0.90 & 2.60 & 0.80 & 4.70 & 1.50 & 2.40 & 0.70. \\
\hline $12.2 \mathrm{ppm} \mathrm{NO} \mathrm{NO}_{3}^{-}$ & 2.50 & 1.50 & 3.10 & 1.10 & 570 & 2.40 & 2.80 & 1.10 \\
\hline $19.7 \mathrm{ppm} \mathrm{I}^{-}$ & 4.60 & 1.30 & 5.60 & 1.10 & 8.25 & 1.60 & 4.75 & 1.10 \\
\hline $27.6 \mathrm{ppm} \mathrm{SO} \mathrm{SO}_{4}^{-2}$ & 13.20 & 3.80 & 18.10 & 4.80 & $>22$ & --- & 10.55 & 2.60 \\
\hline
\end{tabular}

$a_{\text {The concentration of each eluent was } 1 \times 10^{-4}} \underline{M}$ and the ion-exchange resin was $0.0057 \mathrm{meq} / \mathrm{g}$ XAD-l for all of the trials. 


\section{0}

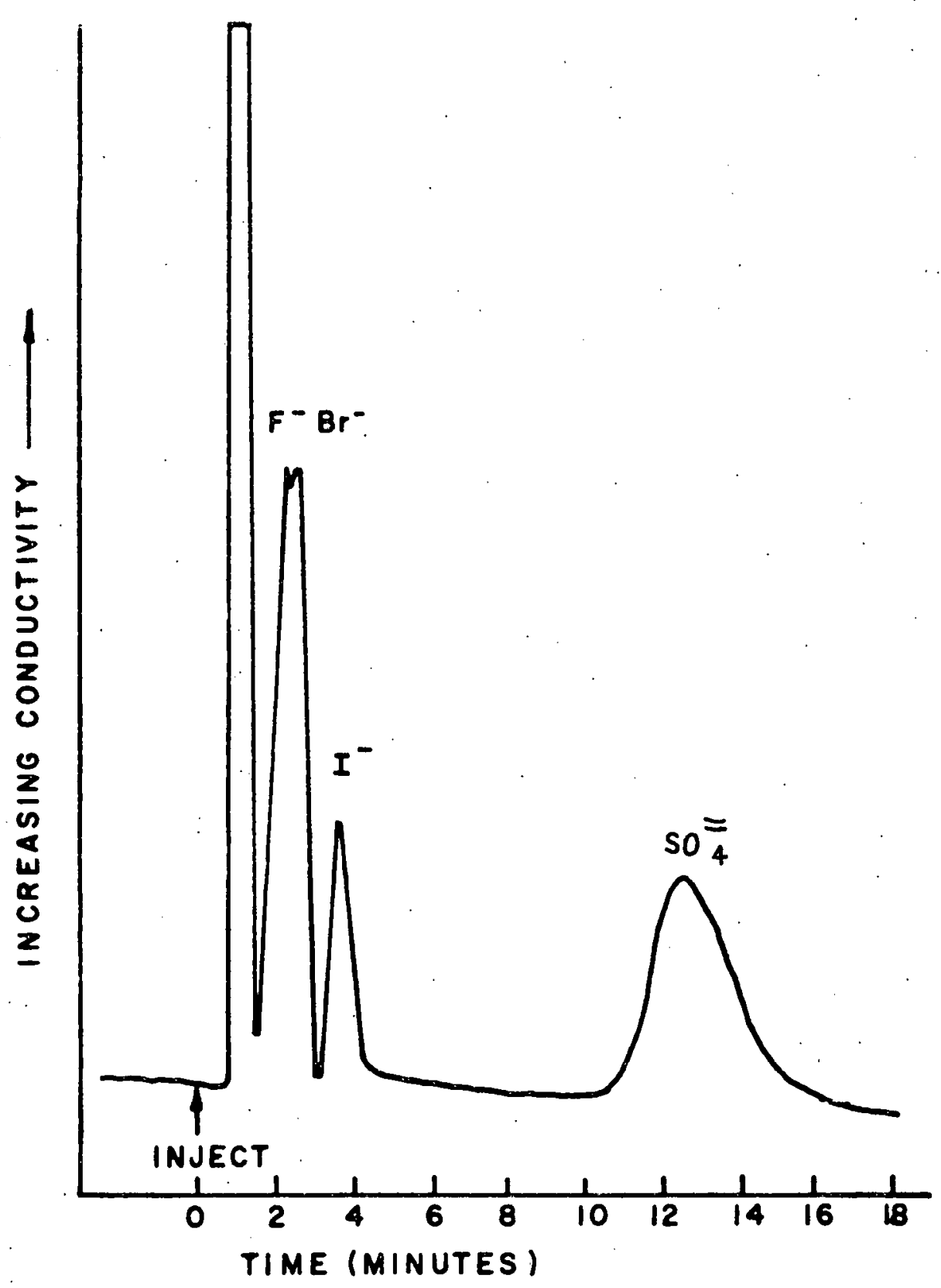

The eluent was $1.65 \times 10^{-4} \mathrm{M}$ o-nitrophenol at a pH of 7.5 . The anion-exchange column was $0.016 \mathrm{meq} / \mathrm{g}$ AN59-XA. The sample was. 4.25 ppin fluortde, $6.0 \mathrm{ppm}$ bromide, $6.8 \mathrm{ppm}$ iodide, and 9.0 ppm sulfate.

Figure 7. Separation of fluoride, bromide, lodide, and sulfale using o-riltrophenol 
meta isomer to be a weaker eluent than the ortho isomer. Because the steric factor decreases the strength of the eluent and the stability factor increases the strength of meta-nitrophenol as compared to para-nitrophenol, it is not possible to predict whether the meta or para isomer should be the stronger eluent. All of the predictions which can be made with this two parameter model, however, do agree with the experimental results. It may be noticed that o-nitrophenol is a very strong eluent, while o-nitrobenzoic acid is a weak eluent. This comparison shows that care must be taken when making predictions about eluents which have different types of acid groups, because it is the differences in the nature of phenols and carboxylic acids which cause the differences in eluent strength. o-Nitrobenzoic acid is a fairly strong acid $\left(\mathrm{pK}_{\mathrm{a}}=2.22\right)$ and the o-nitrobenzoate anion is stabilized by a good deal of charge dispersal throughout the anion. In fact, it is this charge dispersal that makes o-nitrobenzoic acid a.weak eluent. The charge is dispersed so well that there is not enough electron density around the carboxylate group to cause the o-nitrobenzoate to be strongly held by the ionexchange sites on the resin.

o-Nitrophenol, however, is a weak acid $\left(\mathrm{pK}_{\mathrm{a}}=7.2\right)$ because the anion is not stabilized by an efficient charge distribution mechanism. This causes most of the charge to 
remain on the oxygen and increases the electrostatic attraction between the phenoxide anion and an ion-exchange site. The $\mathrm{O}^{-}$group is smaller than the $\mathrm{COO}^{-}$group. This size difference allows the phenoxide ion to approach an ionexchange site more closely than a benzoate ion and also increases the electrostatic attraction between the phenoxide ion and the exchange site. Both of these effects should increase the eluent strength of o-nitrophenol as compared to the eluent strength o-nitrobenzoic acid. These factors must be considered in addition to the usual factors before any predictions about the relative strength of different types of eluents can be madc.

\section{Sulfonic acids}

A study of the eluent properties of compounds containing sulfonic acid groups was undertaken to determine if they could be used as alternatives to carboxylic acid eluents. The eluents in this study were $1 \times 10^{-4} \mathrm{M}$ solutions of benzenesulfonic, sulfanilic, and sulfobenzoic acids. The $\mathrm{pH}$ of these solutions was adjusted to $7.8,8.0$, and 7.8 , respectively. All of the trials were run on the $0.0057 \mathrm{meq} / \mathrm{g}$ XAD-1 anion exchange column with an eluent flow rate of $1.5 \mathrm{ml} / \mathrm{min}$.

The results of the chromatographic trials are given in Table 5. These results indicate that the efficiency of the 
Table 5. Sulfonic and mixed sulfonic acids ${ }^{a}$

\begin{tabular}{|c|c|c|c|c|c|c|}
\hline \multirow[t]{2}{*}{ Sample } & \multicolumn{2}{|c|}{ benzenesulfonic acid } & \multicolumn{2}{|c|}{ sulfanilic acid ${ }^{c}$} & \multicolumn{2}{|c|}{ sulfobenzoic acid } \\
\hline & $\mathrm{T}_{\mathrm{R}}^{\prime}(\min )$ & $w_{\frac{1}{2}}(\min )$ & $\mathrm{T}_{\mathrm{R}}^{\prime}(\min )$ & $W_{\frac{1}{2}}(\min )$ & $\mathrm{T}_{\mathrm{R}}^{\prime}(\min )$ & $W_{\frac{1}{2}}(\min )$ \\
\hline $9.9 \mathrm{ppm} \mathrm{F}$ & 4.60 & 1.40 & $5 \cdot 30$ & 1.60 & 1.80 & 0.60 \\
\hline $10.3 \mathrm{ppm} \mathrm{Cl}^{-}$ & 4.60 & 1.10 & 4.80 & 1.30 & 1.90 & 0.60 \\
\hline $13.0 \mathrm{ppm} \mathrm{Br}-$ & $5 \cdot 9.0$ & 2.10 & 6.60 & 1.80 & 1.80 & 0.60 \\
\hline $12.2 \mathrm{ppm} \mathrm{NO}_{3}^{-}$ & $7 \cdot 30$ & 2.40 & 12.00 & 2.00 & 2.70 & 0.90 \\
\hline $19.7 \mathrm{ppm} \mathrm{I}$ & 12.10 & 2.50 & 13.50 & 3.00 & $4 \cdot 30^{\mathrm{d}}$ & 1.10 \\
\hline $27.6 \mathrm{ppm} \mathrm{SO}_{4}^{-2}$ & --- & -- & $-\cdots$ & -- & 8.70 & 2.20 \\
\hline
\end{tabular}

$a_{\text {The concentration of each eluent was } 1 \cdot \times 10^{-4}} \underline{M}$ and the ion-exchange resin was $0.0057 \mathrm{meq} / \mathrm{g} \mathrm{XAD-1}$.

${ }^{\mathrm{b}}$ An additional peak appears in all chromatograms at $\mathrm{T}_{\mathrm{R}}^{\prime}=7.80$ with $\mathrm{W}_{\frac{1}{2}}=1.80$.

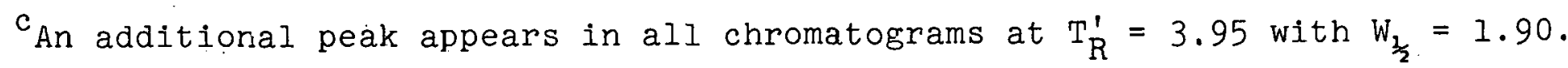

$\mathrm{d}_{\text {An }}$ additional peak appears with the iodide sample at $\mathrm{T}_{\mathrm{R}}^{\prime}=7.80$ with $\mathrm{W}_{\frac{1}{2}}=1.80$. 
sulfonic acid eluents decreases in the following order: sulfobenzoic acid > benzenesulfonic acid > sulfanilic acid. The results of these trials were very disappointing. The retention times for common inorganic anions are roughly the same for sulfobenzoic and phthalic acids. but when sulfobenzoic acid is used as the eluent, the peaks are considerably broader. Sulfobenzoic acid also exhibits no selectivity differences among fluoride, chloride and bromide ions, which would cause problems in the analysis of most real samples.

Benzenesulfonic and sulfanilic acids are also poor eluents: Not only are fluoride, chloride and bromide unseparable, but an additional peak appears in all of the chromatograms. This peak does not appear to be caused by carbonate ions, but seems to be an intrinsic part of these eluent systems. It is probably caused by some type of easily reversible absorption of the eluent onto the resin. A similar problem occurs with trimesic acid at low $\mathrm{pH}$ values and the problem is discussed in detail in the section dealing with that eluent. These eluents are also very corrosive and difficult to purchase in high purity. For all of these reasons, the use of sulfonic acids as eluents is not recommended. 
Phosphonic and phosphinic acids

A study of the eluent properties of compounds with a phosphorus-containing acid group was undertaken to determine if they would be effective eluents. The eluents were $1 \times 10^{-4} \mathrm{M}$ solutions of phenylphosphinic and phenylphosphonic acids. The $\mathrm{pH}$ of the phenylphosphinic acid was adjusted to 6.80 while two solutions of phenylphosphonic acid were prepared and adjusted to $\mathrm{pH} 6.05$ and $\mathrm{pH} 8.00$. of the trials were run on the $0.0057 \mathrm{meq} / \mathrm{g}$ XAD-1 anion exchange column with an eluent flow rate of $1.5 \mathrm{ml} / \mathrm{min}$.

The results of the chromatographic trials are given in Table 6. These results indicate that the efficiency of phosphorus-containing eluents decreases in the following order: phenylphosphonic acid $(\mathrm{pH}$ 8.6).> phenylphosphinic acid (6.8) > phenylphosphonic acid ( $\mathrm{pH}$ 6.1).

It is expected that phenylphosphonic acid at $\mathrm{pH} 8.60$ should be the strongest phosphorus-containing eluent because it forms a completely dissociated divalent anion above a $\mathrm{pH}$ of 8.4 . The other eluents in this study form only monovalent anions at the lower $p H$ value used for their evaluation. Both the structures and the first dissociation constants of phenylphosphonic and phenylphosphinic acids are very similar $\left(\mathrm{pK}_{\mathrm{a}}=2.2\right.$ vs. 2.I) so no predictions could be made about the relative strength of these eluents. 
Table 6. Phosphonic and pjosphinic acids ${ }^{a}$

\begin{tabular}{|c|c|c|c|c|c|c|}
\hline \multirow[t]{2}{*}{ Sample } & \multicolumn{2}{|c|}{$\begin{array}{c}\text { prenylphosphinic acid } \\
\mathrm{pH}=6.8 \mathrm{D}\end{array}$} & \multicolumn{2}{|c|}{$\begin{array}{c}\text { phenylphosphonic acid } \\
\text { pH }=6.05\end{array}$} & \multicolumn{2}{|c|}{$\begin{array}{c}\text { phenyl phosphonic acid } \\
\text { pH }=8.60\end{array}$} \\
\hline & $\mathrm{T}_{\mathrm{R}}^{\prime}(\min )$ & $\mathrm{W}_{\frac{1}{2}}(\min )$ & $\mathrm{T}_{\mathrm{R}}^{\prime}(\min )$ & $W_{\frac{1}{2}}(\min )$ & $\mathrm{T}_{\mathrm{R}}^{\prime}(\min )$ & $\mathrm{W}_{\frac{1}{2}}(\min )$ \\
\hline $9.9 \mathrm{ppm} \mathrm{F}$ & 5.30 & 1.50 & 6.10 & 1.90 & 2.30 & 0.70 \\
\hline $10.3 \mathrm{ppm} \mathrm{Cl}^{-}$ & 6.25 & $1.60^{\circ}$ & $7 \cdot 30$ & 1.60 & 2.60 & 1.00 \\
\hline $13.0 \mathrm{ppm} \mathrm{Br}-$ & 7.95 & 2.40 & 9.95 & 1.90 & 3.50 & 1.00 \\
\hline $12.2 \mathrm{ppm} \mathrm{NO}_{3}^{-}$ & 9.65 & 2.80 & 10.50 & 2.30 & 4.20 & 1.30 \\
\hline $19.7 \mathrm{ppm} \mathrm{I^{- }}$ & 19.70 & 3.70 & $>20$ & -- & 7.50 & 1.60 \\
\hline $27.6 \mathrm{ppm} \mathrm{SO} \mathrm{SO}_{4}^{-2}$ & -- & --- & -- & $-\cdots$ & 20.10 & 4.80 \\
\hline
\end{tabular}

$a_{\text {The concentration of each eluent was } I \times 10^{-4}} \underline{\mathrm{M}}$ and the ion-exchange resin was $0.0057 \mathrm{meq} / \mathrm{g}$ XAD-1.

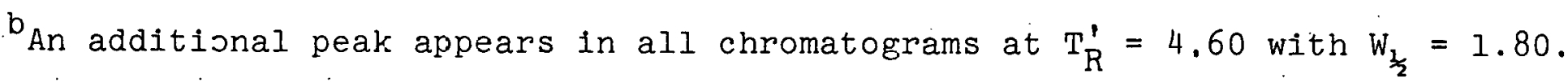

${ }^{c}$ An additional peak appears in all chromatograms at $T_{R}^{\prime}=10.20$ with $W_{\frac{1}{2}}=1.80$.

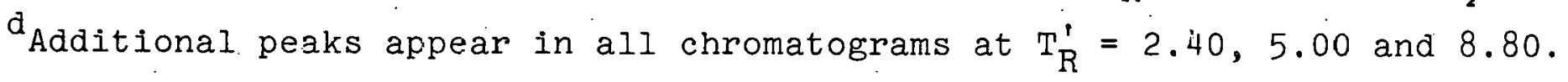


The phosphorus containing eluents offer no improvement in either retention time or selectivity over the commonly used carboxylic acid eluents. The monovalent acids are slightly weaker than benzoic acid and they produce wider . peaks than benzoic acid. The retention times produced with phenylphosphonic acid at a pH of 8.60 are approximately twice as long as the retention times produced with phthalic acid. In addition to these facts, an extra peak appears in all of the chromatograms. This peak seems to be an intrinsic part of these eluents systems and is probably caused by an easily reversible absorption of the eluent onto the resin. A similar problem occurs with trimesic acid at low $\mathrm{pH}$ values and the problem is discussed in detail in the section dealing with that eluent. For all of these reasons, the use of phenylphosphonic and phenylphosphinic eluents is not recommended.

Additional Data on 1,3,5-Benzenetricarboxylic Acid

Chromatograph1c conditions

An extended study of 1,3,5-benzenetricarboxylic acid (trimesic acid) was carried out. It was hoped that because trimesic is a very strong eluent, a number of highly retained species could be eluted and the analysis times for multivalent ions could be reduced. This study involved determining the suitability of trimesic acid as an eluent 
for the common inorganic anions, carboxylic acids, and sulfonic acids. The characteristics of the eluent as the $\mathrm{pH}$ was changed from 4.0 to 8.0 were also studied while performing this survey. All of the chromatographic trials were performed on the $0.016 \mathrm{meq} / \mathrm{g}$ AN59-XA anion-exchange column with a flow rate of $1.6 \mathrm{ml} / \mathrm{min}$. The eluent was $1.25 \times 10^{-4}$ M trimesic acid which had the $\mathrm{pH}$ adjusted from 4.0 to 8.0 in increments of one $\mathrm{pH}$ unit.

\section{The eluent peak}

When the pH survey was performed, an extra peak was found in all of the chromatograms produced with the eluent at a $\mathrm{pH}$ of 4.0 . This peak had an adjusted retention time of 6.5 minutes and did not correspond to any known sample components. Furthermore, both positive and negative peaks were formed because this extra peak sometimes had a higher conductivity and sometimes had a lower conductivity than the eluent background (see Figure 8). A similar type of peak occurred for some samples at an eluent $\mathrm{pH}$ of 5.0 , but it was never observed at a $\mathrm{pH}$ of 6.0 or higher when trimesic acid was used as the eluent.

The formation of both positive and negative peaks under the same eluent conditions is an indication that the peaks are not caused by ion exchange. The 1on-exchange process consists of removing one ion from solution and replacing it with another ion. The exchanged fon can have either a 


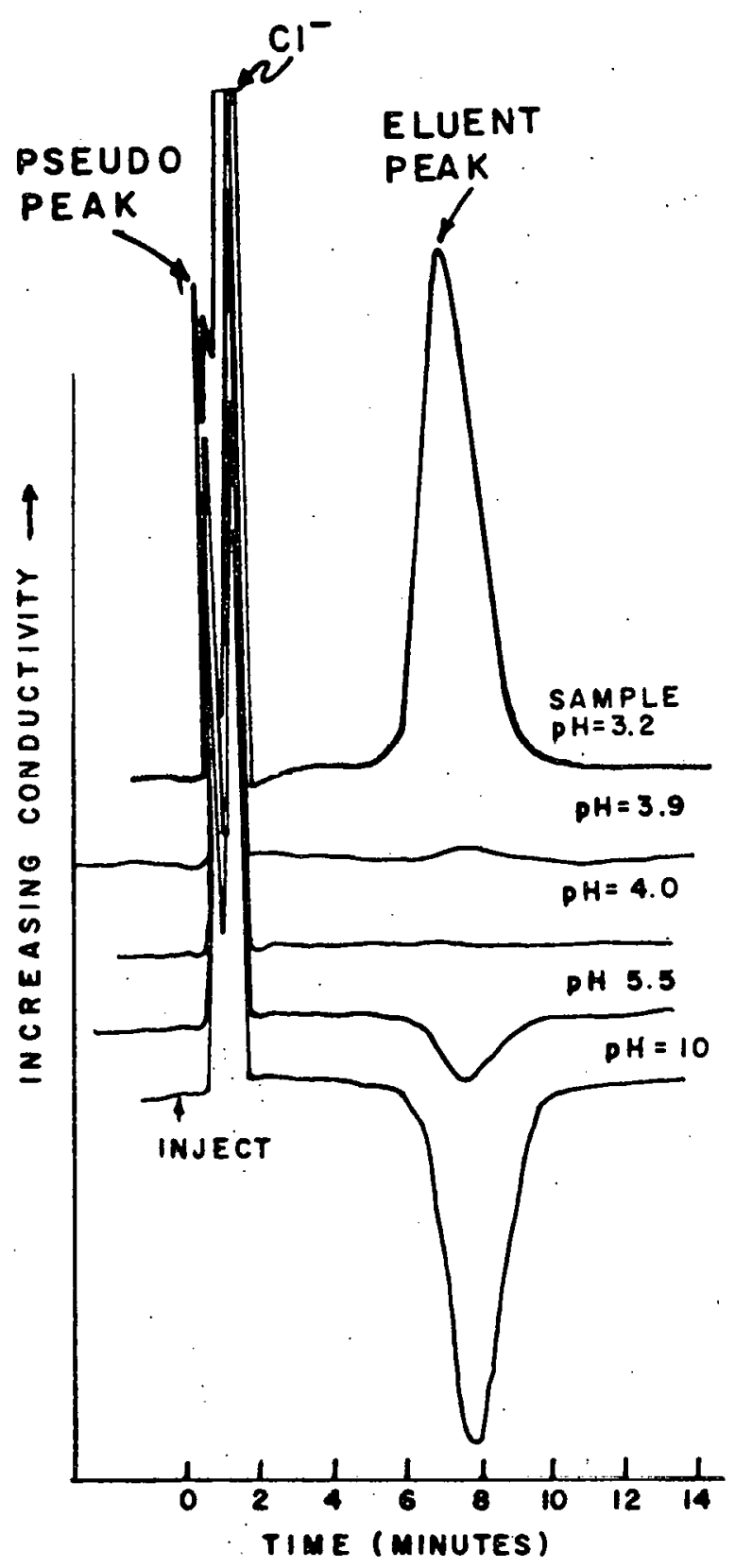

The eluent was $1.25 \times 10^{-4} \mathrm{M}$ trimesic acid at a $\mathrm{pH}$ of 4.0 . The anion-exchange column was $0.016 \mathrm{meq} / \mathrm{g}$ AN59-XA. The samples were $10 \mathrm{ppm}$ chloride at a sample $\mathrm{pH}$ of $5.5,10 \mathrm{ppm}$ chloride with $\mathrm{KOH}$ added at a $\mathrm{pH}$ of 10 , and $10 \mathrm{ppm}$ chloride with $\mathrm{HCl}$ added for the samples with a $\mathrm{pH}$ below 5.5 .

Figure 8. The eluent peak 
higher or a lower conductivity than the eluent, but a single ion cannot sometimes be more conducting and sometimes be less conducting than the eluent.'

Both positive and negative peaks can be produced, however, by an adsorption/desorption mechanism, and this process is likely to occur for the anion-exchange column because most organic molecules are adsorbed on XAD resins [9]. If the injection of a particular sample causes some species in the eluent to be adsorbed from solution onto the resin, a negative peak will occur. If the injection of a sample causes some species to desorb from the resin into the eluent, a positive peak will occur. Once it is assumed that this process is actually occurring in the ion-exchange column, it becomes necessary to determine what species is undergoing adsorption/desorption and why some samples cause adsorption while others cause desorption.

It was first thought that some impurity in the eluent was being adsorbed onto the resin. In order to test this possibility, a new eluent consisting of a $1 \times 10^{-4} \mathrm{M}$ solution of 1,2,4,5-benzenetertacarboxylic acid (pyromellitic acid) at a $\mathrm{pH}$ of 4.0 was used. This eluent was equilibrated with the resin, and a number of common inorganic anion samples were injected. An extra peak appeared in all of the chromatograms and exhibited the same behavior as with trimesic acid. Later studies showed that 
this extra peak was also present when sulfonic, phosphonic and phosphinic acids were used as eluents. It is very unlikely that an impurity would be present in all of these eluents and that the impurity would exhibit the same behavior in all of them. Therefore, this peak must be an intrinsic part of these eluent systems and will be referred to as the eluent peak.

In order to further demonstrate that the eluent peak was not caused by an ion-exchange process, a $50^{\circ} \mathrm{cm}$ glass column was packed with 250-325 mesh unfunctionalized XAD-1 and the $1 \times 10^{-4} \mathrm{M}$ pyromellitic acid eluent was pumped through it. Dilute solutions of strong acids and bases were injected onto the column and their elution was followed using the conductivity detector. Because ion exchange could not take place and because inorganic ions are not adsorbed by $X A D-1$, any peaks which were retained by the resin must be caused by adsorption of the eluent. The results of these experiments are given in Table 7 and indicate that adsorption does take place. These results also indicate that positive peaks result from samples which are more acidic than the eluent, while more basic samples cause negative peaks.

The eluent peak has a higher conductivity than the $:$ baseline for samples which are more acidic than the eluent because of increased adsorption. When the acidic sample is 
Table 7. Eluent peaks on unfunctionalized XAD-1 ${ }^{a}$

\begin{tabular}{|c|c|c|c|c|}
\hline Sample & $\mathrm{T}_{\mathrm{R}}^{\prime}(\min )$ & $\mathrm{W}_{\frac{1}{2}}(\min )$ & Height $(\mathrm{cm})$ & \\
\hline $\mathrm{HCl}(\mathrm{pH} 3.3)$ & 4.60 & 1.90 & +10.7 & \\
\hline $\mathrm{HNO}_{3}\left(\mathrm{pH}_{3} 3.3\right)$ & 4.50 & 1.90 & +12.2 & \\
\hline $\mathrm{H}_{2} \mathrm{SO}_{4}(\mathrm{pH} 3.3)$ & 4.80 & 1.80 & +12.9 & \\
\hline $\mathrm{HCl}(\mathrm{pH} \cdot 4.0)$ & 5.80 & 1.80 & +0.8 & \\
\hline $\mathrm{HCl}(\mathrm{pH} 4.3)$ & --- & --- & --- & \\
\hline $\mathrm{KOH}(\mathrm{pH} 6.0)$ & 6.00 & 1.70 & -1.0 & : \\
\hline $\mathrm{KOH}(\mathrm{pH} 8.2)$ & 6.10 & 1.80 & -1.7 & \\
\hline $\mathrm{KOH}(\mathrm{pH} 10.0)$ & 6.10 & 2.00 & -6.4 & \\
\hline
\end{tabular}

$a_{\text {The eluent was } a} 1 \times 10^{-4}$ M solution of pyromellitic acid with a pH of 4.5 . 
injected, it shifts the equilibrium in the column and causes some of the eluent $\left(\mathrm{E}^{-}\right)$to become protonated (HE). The protonated eluent is then adsorbed onto the resin as shown in Equation 3.

$\operatorname{Resin} \longrightarrow \mathrm{HE} \longrightarrow \mathrm{H}^{+}+\mathrm{E}^{-} \quad(\mathrm{Eq} \cdot 3)$

For simplicity, assume that the amount of eluent adsorbed onto the resin is equal to the amount of acid (HCl) in the sample. The system now has replaced $X$ amount of eluent with $\mathrm{X}$ amount of $\mathrm{HCl}$ in solution. This portion of the eluent moves down the column and undergoes ion exchange (see Equation 4). The $\mathrm{X}$ amount of $\mathrm{CI}^{-}$has now been replaced with $X$ amount of $E^{-}$and equilibrium is restored at the solvent front. The counter ion remains the same throughout. this process.

$$
\operatorname{Resin-N}\left(\mathrm{CH}_{3}\right)_{\mathrm{E}^{-}}+\mathrm{H}^{+}+\mathrm{Cl}^{-} \underset{\oplus_{\mathrm{Cl}^{-}}}{\longrightarrow} \operatorname{Resin}-\mathrm{N}_{3}\left(\mathrm{CH}_{3}\right)_{3}+\mathrm{H}^{+}+\mathrm{E}_{(\mathrm{Eq} \cdot 4)}^{-}
$$

Meanwhile, there is an excess of $\mathrm{HE}$ on the resin at the top of the column. When a fresh portion of eluent moves past this section of the resin, the equilibrium will shift to the right in Fquation 3 and the adsorbed eluent will return to solution. Because fresh eluent is always flowing past this section of resin, all of the adsorbed eluent will eventually return to solution. As the solution containing the additional desorbed eluent moves down the column, it 
will encounter fresh resin. The equilibrium will shift again and the excess eluent will continue partitioning its way down the column until it reaches the detector. The extra eluent in solution will then cause an increase in conductance to occur causing a positive peak.

The eluent peak has a lower conductivity than the eluent for samples which are more basic than the eluent because of increased desorption. When the basic sample is injected, it shifts the equilibrium in Equation 3 to the right and causes some of the adsorbed eluent (HE) to be ionized $\left(F^{-}\right)$and return to solution.

For simplicity, assume that the amount of eluent desorbed into solution, $Y$, is equal to the amount of base $(\mathrm{KOH})$. in the sample. The system now has a deficiency of $Y$ amount of $\mathrm{HE}$ adsorbed on the resin. When fresh eluent reaches the position of the desorbed eluent "hole", the equilibrium will shift and some of the eluent in solution will be adsorbed by the resin to fill the "hole". This, in turn, depletes the solution of eluent molecules and the solution will shift the equilibrium in Equation 3 to the right to obtain more eluent molecules when it reaches fresh resin. In this way, the hole moves down the column and reaches the detector. The reduction in the amount of eluent in solution will cause a decrease in conductance to occur and a negative peak will be formed. 
It should be noted that for samples more basic than the eluent, the solvent front does not achieve equilibrium. The $\mathrm{KOH}$ reacts with the $\mathrm{H}^{+}$in the eluent to form $\mathrm{H}_{2} \mathrm{O}$. The net result of this reaction is to change the counter ion of the eluent from $\mathrm{H}^{+}$to $\mathrm{K}^{+}$, as shown in Equation 5. Because the excess eluent in solution is now a $\mathrm{K}^{+}$salt, it remains in solution and moves through the column much more quickly than does the acid form. The $\mathrm{K}^{+}$salt must come off with the pseudo peak because only one extra peak is observed. If it was adsorbed by the resin, a second eluent peak, which would occur in the positive direction, would be observed.

$$
\mathrm{H}^{+}+\mathrm{E}^{-}+\mathrm{K}^{+}+\mathrm{OH}^{-} \rightleftarrows \mathrm{H}_{2} \mathrm{O}+\mathrm{K}^{+}+\mathrm{E}^{-} \quad \text { (Eq. 5) }
$$

The eluent peak is caused by an adsorption phenomena and only occurs when the eluent is not highly ionized. This dependence on the degree of ionization of the eluent explains why the eluent peak occurs at a $\mathrm{pH}$ of 5.0 and below, and why it does not occur at a pH of 6.0 or above when trimesic acid is used as the eluent. Although an extensive study was not performed, the other carboxylic acids surveyed should also begin to produce eluent peaks as the $\mathrm{pH}$ is lowered. These acids should produce eluent peaks at a fairly high pH, probably around 6, because they have fewer acid groups and are generally weaker acids than trimesic acid. The nitrophenols are even weaker acids, and 
it would not be surprising if eluent peaks were present at a pH of 6.5 or even 7.0 for these eluents.

If an eluent peak is present, it can be eliminated in a number of ways. The simplest method to eliminate the eluent peak is to use an eluent, such as citric acid, which is not adsorbed on the ion-exchange resin. Another method to eliminate this peak is to raise the $\mathrm{pH}$ of the eluent until adsorption on the resin no longer takes place. As discussed above, a pH of 6.5 and 7.5 should be high enough to eliminate the eluent peak for carboxylic acids and nitrophenols.

It is desirable to be able to use some eluents at a low $\mathrm{pH}$ because the selectivity for certain compounds is improved as the $\mathrm{pH}$ is lowered. In this case, the eluent peak can be eliminated by adjusting the $\mathrm{pH}$ of the sample to match the $\mathrm{pH}$ of the eluent. This eliminates the change in $\dot{\mathrm{pH}}$ during the injection and the eluent peak is not produced. If the $\mathrm{pH}$ of the sample is raised to match the $\mathrm{pH}$ of the eluent, no additional peaks will be formed because the added $\mathrm{OH}^{-}$ions elute with the pseudo peak. If the pH of the sample is lowered to match the $\mathrm{pH}$ of the eluent, an additional peak is produced by the anion of the added acid. This peak, however, is usually narrower than the eluent peak. The position of this peak in the chromatogram can be shifted so. that it does not interfere with the separation by carefully choosing the acid used to adjust the pH. 
Another way to eliminate the eluent peak is to dissolve the anion sample in the eluent used for the analysis. This eliminates most of the changes usually associated with the injection of a sample and the eluent peak is never formed. This procedure is the same as the standard method used by the Dionex Corp. to eliminate their "water dip."

\section{Inorganic anions}

The results of the extended study of trimesic acid as an eluent for inorganic anions are presented in Table 8. These results show that trimesic acid is too strong an eluent for most monovalent inorganic anions. The three most common halide anions $\left(\mathrm{F}^{-}, \mathrm{Cl}^{-}\right.$, and $\left.\mathrm{Br}^{-}\right)$elute in less than 1.2 minutes and are not resolved from each other. Above an eluent $\mathrm{pH}$ of 5.0 , all of the divalent anions are removed from the column in less than 2.0 minutes and little selectivity is observed. At an eluent pH of 4.0, however, the selectivity for a number of strongly retained anions improves dramatically and a number of separations should be possible.

\section{Carboxylic acids}

The results of the extended study of trimesic acid as an eluent for carboxylic acids are presented in Table 9 . These results show that carboxylic acids are eluted very efficiently, with benzoic acid being eluted in less than 
Table 8. 1,3,5-Benzenetricarboxylic acid as an eluent for inorganic anions ${ }^{a}$

\begin{tabular}{|c|c|c|c|c|c|c|c|c|c|c|}
\hline Sample & \multicolumn{2}{|c|}{$\begin{array}{c}\mathrm{pH}=4.0^{\mathrm{b}} \\
\mathrm{T}_{\mathrm{R}}^{\prime} \mathrm{W}_{\frac{1}{2}} \\
(\mathrm{~min})(\mathrm{min})\end{array}$} & $\begin{array}{l}\mathrm{pH}= \\
\mathrm{T}_{\mathrm{R}}^{\prime} \\
(\min )\end{array}$ & $\begin{array}{l}5.0 \\
W_{\frac{1}{2}} \\
\text { (min) }\end{array}$ & $\begin{array}{l}\mathrm{pH}= \\
\mathrm{T}_{\mathrm{R}}^{\prime} \\
(\min )\end{array}$ & $\begin{array}{l}6.0 \\
W_{\frac{1}{2}} \\
(\min )\end{array}$ & $\begin{array}{c}\mathrm{pH}= \\
\mathrm{T}_{\mathrm{R}}^{\prime} \\
(\min )\end{array}$ & $\begin{array}{l}7.0 \\
W_{\frac{1}{2}} \\
(\min )\end{array}$ & $\begin{array}{l}\mathrm{pH}= \\
\mathrm{T}_{\mathrm{R}}^{\prime} \\
(\min )\end{array}$ & $\begin{array}{l}8.0 \\
W_{\frac{1}{2}} \\
\text { (min) }\end{array}$ \\
\hline $9.9 \mathrm{ppm} \mathrm{F}^{-}$ & 0.90 & 0.30 & 0.50 & 0.30 & 0.40 & 0.30 & 0.50 & 0.30 & 0.50 & 0.30 \\
\hline $10.3 \mathrm{ppm} \mathrm{C1}^{-}$ & 1.10 & 0.35 & 0.60 & 0.30 & 0.60 & PPI & 0.55 & 0.30 & 0.55 & 0.30 \\
\hline $13.0 \mathrm{ppm} \mathrm{Br}-$ & 1.20 & 0.30 & 0.70 & 0.30 & 0.70 & 0.30 & 0.65 & 0.30 & 0.80 & 0.40 \\
\hline $19.7 \mathrm{ppm} \mathrm{I}^{-}$ & 2.90 & 0.55 & 1.40 & 0.35 & 1.45 & 0.30 & 1.50 & 0.35 & 1.20 & 0.40 \\
\hline $27.6 \mathrm{ppm} \mathrm{SO} \mathrm{SO}_{4}^{-2}$ & 6.20 & 0.70 & 1.90 & 0.55 & 1.90 & 0.60 & 1.80 & 0.60 & 1.50 & 0.50 \\
\hline $24.4 \mathrm{ppm} \mathrm{PO}_{4}^{-3}$ & 0.80 & 0.35 & 0.70 & 0.30 & 0.50 & 0.30 & 0.70 & 0.40 & 0.70 & 0.40 \\
\hline $29.0 \mathrm{ppm} \mathrm{CrO}_{4}^{-2}$ & 1.90 & 0.70 & 1.00 & 0.50 & 1.50 & 0.40 & 1.50 & 0.50 & 1.30 & 0.40 \\
\hline
\end{tabular}

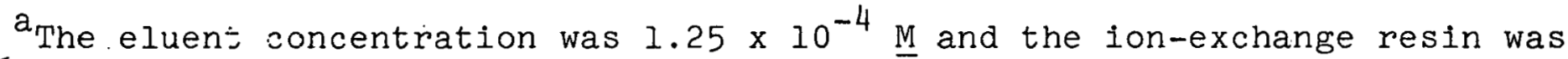
$0.016 \mathrm{meq} / \mathrm{g}$ AN59-XA for all of the trials.

${ }^{b}$ An additional peak appears in all chromatograms at $\mathrm{T}_{\mathrm{R}}^{\prime}=6.60$ with $\mathrm{w}_{\frac{1}{2}}=1.50$. 
Table 9. 1,3,5-Benzenetricarborylic acid as an eluent for carboxylic acids

\begin{tabular}{|c|c|c|c|c|c|c|c|c|c|c|}
\hline Sample & $\begin{array}{c}\mathrm{pH}= \\
\mathrm{T}_{\mathrm{R}}^{\prime} \\
(\min )\end{array}$ & $\begin{array}{l}4.0^{b} \\
W_{\frac{1}{2}} \\
\text { (min) }\end{array}$ & $\begin{array}{c}\mathrm{pH}= \\
\mathrm{T}_{\mathrm{R}}^{\prime} \\
(\min )\end{array}$ & $\begin{array}{c}5.0 \\
W_{\frac{1}{2}} \\
(\mathrm{~min})\end{array}$ & $\begin{array}{c}\mathrm{pH}= \\
\mathrm{T}_{\mathrm{R}}^{\prime} \\
(\min )\end{array}$ & $\begin{array}{l}6.0 \\
W_{\frac{1}{2}} \\
(\mathrm{~min})\end{array}$ & $\begin{array}{c}\mathrm{pH}= \\
\mathrm{T}_{\mathrm{R}}^{\prime} \\
(\text { min) }\end{array}$ & $\begin{array}{l}7.0 \\
w_{\frac{1}{2}} \\
(\mathrm{~min})\end{array}$ & $\begin{array}{c}\mathrm{pH}= \\
\mathrm{T}_{\mathrm{R}}^{\prime} \\
(\min )\end{array}$ & $\begin{array}{l}8.0 \\
W_{\frac{1}{2}} \\
(\mathrm{~min})\end{array}$ \\
\hline $\begin{array}{l}73 \mathrm{ppm} \text { formate. } \\
\left(\mathrm{CHCO}_{2}^{-}\right)\end{array}$ & 0.90 & 0.30 & 1.30 & 0.45 & 0.70 & 0.25 & 0.30 & 0.35 & 0.50 & 0.30 \\
\hline $\begin{array}{l}27.1 \mathrm{ppm} \text { acetate } \\
\left(\mathrm{CH}_{3} \mathrm{CO}_{2}^{-}\right)\end{array}$ & 0.75 & $P P I^{c}$ & 0.60 & 0.25 & 0.50 & 0.25 & 0.55 & 0.30 & 0.50 & 0.30 \\
\hline $\begin{array}{l}100 \text { ppm propionate } \\
\left(\mathrm{C}_{2} \mathrm{H}_{5} \mathrm{CO}_{2}^{-}\right)\end{array}$ & 1.30 & 1.00 & 0.85 & 0.55 & 0.80 & 0.30 & 0.65 & 0.40 & 0.55 & PPI \\
\hline $\begin{array}{l}75 \mathrm{ppm} \text { malate } \\
\left(-\mathrm{O}_{2} \mathrm{CC}_{2} \mathrm{H}_{3}(\mathrm{OH}) \mathrm{CO}_{2}^{-}\right)\end{array}$ & 1.40 & 0.40 & 1.30 & 0.50 & 1.30 & 0.50 & 1.50 & 0.45 & 1.30 & 0.50 \\
\hline $\begin{array}{l}51 \mathrm{ppm} \text { benzoate } \\
\left(\mathrm{C}_{6} \mathrm{H}_{6} \mathrm{CO}_{2}^{-}\right)\end{array}$ & 4.10 & 1.10 & 9.60 & 2.80 & 6.80 & 2.40 & 6.40 & 1.90 & 6.40 & 1.90 \\
\hline $\begin{array}{l}53 \mathrm{ppm} \text { pheriylacetate } \\
\left(\mathrm{C}_{6} \mathrm{H}_{6} \mathrm{CH}_{2} \mathrm{CO}_{2}^{-}\right)\end{array}$ & -- & -- & 9.70 & 2.70 & 8.50 & 2.50 & 8.80 & 2.80 & 8.20 & 2.60 \\
\hline
\end{tabular}

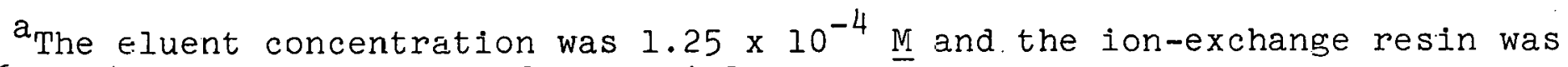
$0.016 \mathrm{meq} / \mathrm{E}$ AN59-XA for all of the trials,

${ }^{\mathrm{b}}$ An acditional peak appears in all chromatograms at $\mathrm{T}_{\mathrm{R}}^{\prime}=660$ with $\mathrm{W}_{\frac{1}{2}}=1.50$.

${ }^{c}$ Pseuco prak interfers with sample ion. 
10 minutes. The results also show that the $\mathrm{pH}$ of the eluent is a useful variable for improving the separation of some carboxylic acids. Acetate and formate can be easily separated at a $\mathrm{pH}$ of 5.0 but they overlap at a $\mathrm{pH}$ of 8.0 . Malate and propionate, on the other hand, are easily separable at an eluent $\mathrm{pH}$ of 8.0 , but overlap at a $\mathrm{pH}$ of 5.0. These selectivity differences are caused by the weak acid nature of the samples and the eluent.

At a $\mathrm{pH}$ of 8.0 , the trimesic acid eluent is present as a totally ionized -3 anion. Under these conditions, trimesic acid is such a strong eluent that it exhibits little selectivity for any monovalent anions. Because the eluent becomes progressively more protonated as the $\mathrm{pH}$ is lowered, it becomes a weaker eluent. It is this decrease in eluent strength which causes the small ion-exchange affinity differences among the sample anions to become more apparent and improves the selectivity between formate and acetate Lons.

The decreased selectivity between malate and propionate is caused by the protonation of the sample anions. At a pH of 8.0, malate is a divalent anion and propionate is a monovalent anion. Malate becomes a -1 anion when the $\mathrm{pH}$ is lowered and the differences in the ion-exchange affinities between the two carboxylate acids decreases. If this process continues, the samples will 
become fully protonated and ion-exchange will no longer occur. This seems to be happening to propionate at a $\mathrm{pH}$ of 4.0. The propionate peak is more than twice as wide as the malate peak which has the same retention time. This is a good indication that the elution of propionate is being controlled by adsorption on the XAD-l portion of the resin and not by ion-exchange.

\section{Sulfonic acids}

The results of the extended study of trimesic acid as an eluent for sulfonic acids are presented in Table 10. These results indicate that small alkylsulfonic acids are easily eluted with trimesic acid and that there are major changes in the relative retention times for a number of these acids between the eluent $\mathrm{pH}^{\prime} \mathrm{s}$ of 4.0 and 5.0 . All the substituted benzenesulfonic acids tested in this study elute in a reasonable time and exhibit remarkable selectivities. All six benzenesulfonic acid derivatives are separated by approximately 1 minute or more when the $\mathrm{pH}$ of the eluent is 5.0. This combination of fast elution and good selectivity makes trimesic acid an excellent eluent for sulfonic acids.

In order to confirm the potential of trimesic acid as an eluent for anion exchange, a number of difficult separations were performed. Figures 9 and 10 both show the 
Table 10. 1;3,5-Benzentricarboxylic acid as an eluent for sulfonic acids ${ }^{a}$

\begin{tabular}{|c|c|c|c|c|c|c|c|c|c|c|}
\hline Sample & $\begin{array}{c}\mathrm{pH}^{\mathrm{i}}= \\
\mathrm{T}_{\mathrm{R}}^{\prime} \\
\text { (min) }\end{array}$ & $\begin{array}{l}4.0^{b} \\
W_{\frac{1}{2}} \\
\text { (min) }\end{array}$ & $\begin{array}{c}\mathrm{pH}= \\
\mathrm{T}_{\mathrm{R}}^{\dot{i}} \\
(\mathrm{~min})\end{array}$ & $\begin{array}{l}5.0 \\
W_{\frac{1}{2}} \\
(\min )\end{array}$ & $\begin{array}{c}\mathrm{pH}= \\
\mathrm{T}_{R}^{\prime} \\
(\mathrm{min})\end{array}$ & $\begin{array}{l}6.0 \\
W_{\frac{1}{2}} \\
\text { (min) }\end{array}$ & $\begin{array}{c}\mathrm{pH}= \\
\mathrm{T}_{\mathrm{R}}^{\prime} \\
(\mathrm{min})\end{array}$ & $\begin{array}{l}7.0 \\
W_{\frac{1}{2}} \\
(\mathrm{~min})\end{array}$ & $\begin{array}{l}\mathrm{pH}^{\prime}= \\
\mathrm{T}_{\mathrm{R}}^{\prime} \\
(\mathrm{min})\end{array}$ & $\begin{array}{l}8.0 \\
W_{\frac{1}{2}} \\
\text { (min) }\end{array}$ \\
\hline $\begin{array}{l}\text { 14.7 ppm methane- } \\
\text { sulfonate }\end{array}$ & $1.1 C$ & 0.35 & WPP ${ }^{c}$ & -- & WPP & -- & WPP & --- & WPP & --- \\
\hline $\begin{array}{l}20.1 \text { ppm sulfo- } \\
\text { acetate }\end{array}$ & $3.6 \mathrm{C}$ & 1.10 & 1.80 & 0.50 & 1.60 & 0.50 & 1.60 & 0.65 & 1.40 & 0.60 \\
\hline $\begin{array}{l}27.5 \mathrm{ppm} \text { ethane- } \\
\text { disulfonate }\end{array}$ & 7.10 & 1.00 & 1.60 & 0.45 & 1.60 & 0.50 & 1.50 & 0.60 & 1.20 & 0.40 \\
\hline $\begin{array}{l}37.8 \text { ppm propane- } \\
\text { sulfonate }\end{array}$ & 2.70 & 0.90 & 1.50 & 0.50 & 1.50 & 0.60 & 1.50 & 0.50 & 1.60 & 0.50 \\
\hline $\begin{array}{l}40.5 \mathrm{ppm} \text { 3-hydroxy- } \\
\text { 1-propane sulfonate }\end{array}$ & $i .00$ & 0.40 & 0.60 & 0.40 & 0.40 & $P P I^{d}$ & 0.50 & 0.35 & 0.40 & PPI \\
\hline $\begin{array}{l}80 \text { ppm benzene- } \\
\text { sulfonate }\end{array}$ & 21.50 & 4.80 & $\begin{array}{r}10.70 \\
-\quad-\end{array}$ & 2.30 & $\begin{array}{r}9.30 \\
-\quad-\end{array}$ & $\begin{array}{r}2.70 \\
-\quad-\end{array}$ & $\begin{array}{l}8.00 \\
-\end{array}$ & 2.50 & $\begin{array}{l}9.60 \\
-\quad-\end{array}$ & 3.10 \\
\hline
\end{tabular}

$a_{\text {The eluent concentration was } 1.25 \times 10^{-4}} \underline{\mathrm{M}}$ and the ion-exchange resin was $0.016 \mathrm{meq} / \mathrm{g}$. AN59-XA for all of the trials.

${ }^{b}$ An additional peak appears in all chromatograms at $T_{R}^{\prime}=6.60$ with $W_{\frac{1}{2}}=1.50$.

${ }^{c}$ Sample elutes with the pseudo peak.

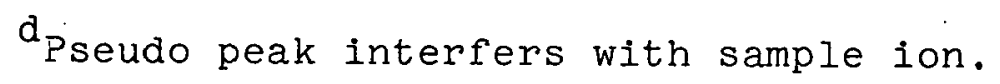


Table 10. (Continued)

\begin{tabular}{|c|c|c|c|c|c|c|c|c|c|c|}
\hline Sample & $\begin{array}{l}\mathrm{pH}= \\
\mathrm{T}_{\mathrm{R}}^{\prime} \\
(\min )\end{array}$ & $\begin{array}{l}4.0^{b} \\
w_{\frac{1}{2}} \\
(\min )\end{array}$ & $\begin{array}{l}\mathrm{pH}= \\
\mathrm{T}_{\mathrm{R}}^{\prime} \\
(\min )\end{array}$ & $\begin{array}{l}5.0 \\
w_{\frac{1}{2}} \\
(\min )\end{array}$ & $\begin{array}{l}\mathrm{pH}= \\
\mathrm{T}_{\mathrm{R}}^{\prime} \\
(\min )\end{array}$ & $\begin{array}{l}6.0 \\
W_{\frac{1}{2}} \\
\text { (min) }\end{array}$ & $\begin{array}{l}\mathrm{pH}= \\
\mathrm{T}_{\mathrm{R}}^{\prime} \\
(\min )\end{array}$ & $\begin{array}{l}7.0 \\
W_{\frac{1}{2}} \\
(\min )\end{array}$ & $\begin{array}{l}\mathrm{pH}= \\
\mathrm{T}_{\mathrm{R}}^{\prime} \\
(\min )\end{array}$ & $\begin{array}{l}8.0 \\
W_{\frac{1}{2}} \\
(\min )\end{array}$ \\
\hline $\begin{array}{l}\equiv 9.6 \text { ppm sulfo- } \\
\text { benzoate }\end{array}$ & 19.30 & 4.70 & 9.70 & 1.30 & 6.50 & 1.80 & 6.85 & 5.80 & 5.70 & 1.60 \\
\hline $\begin{array}{l}43.0 \text { ppm } 4 \text {-amir:o- } \\
\text { benzenesulforate }\end{array}$ & 2.60 & 0.70 & 1.65 & 0.55 & 1.50 & 0.50 & 1.50 & 0.55 & 1.30 & 0.50 \\
\hline $\begin{array}{l}49.4 \mathrm{ppm} 2 \text {-amino- } \\
\text { toluene-5-sulfonate }\end{array}$ & 6.50 & 1.50 & 5.40 & 1.30 & 4.20 & 1.10 & 3.40 & 1.10 & 3.10 & 1.00 \\
\hline $\begin{array}{l}\text { 44. } 8 \mathrm{ppm} 4 \text {-amino- } \\
\text { toluene-2-sulfonate }\end{array}$ & 7.00 & 1.40 & 6.50 & 1.60 & 6.60 & 2.10 & 7.40 & 2.40 & 6.80 & 1.90 \\
\hline $\begin{array}{l}45.8 \mathrm{ppm} 2 \text {-aminio- } \\
\text { toluene-4-sulfonate }\end{array}$ & 6.50 & 1.50 & 8.80 & 2.20 & 8.70 & 2.70 & 9.00 & 3.20 & 8.90 & 2.10 \\
\hline
\end{tabular}


separation of three substituted aromatic sulfonic acids. The last pair of peaks, which have baseline resolution in both chromatograms, are caused by three geometric isomers of aminotoluenesulfonic acid. The separation of these isomers shows the remarkable selectivity of this eluent and ionexchange resin for aromatic sulfonic acids. A separation of sulfanillc, 2,5-aminotoluenesulfonic and benzolc acids is presentcd in Figure 11. The elution of the benzoate anion demonstrates the eluent strength of trimesic acid, because benzoic acid has a high enough affinity for the resin to be used as an ion-exchange eluent itself. The last chromatogram, Figure 12, shows the separation of ethanesulfonic and propanesulfonic acids, which are small highly ionic anions, from 2,5-aminotoluenesulfonic and benzoic acids, which are large hydrophobic anions. In addition to separating the aromatic acids from the aliphatic acids, the individual anions in these two groups are also well resolved. This shows the versalility of the eluent and illustrates the possibility of using trimesic acid to separate a variety of organic anions. 


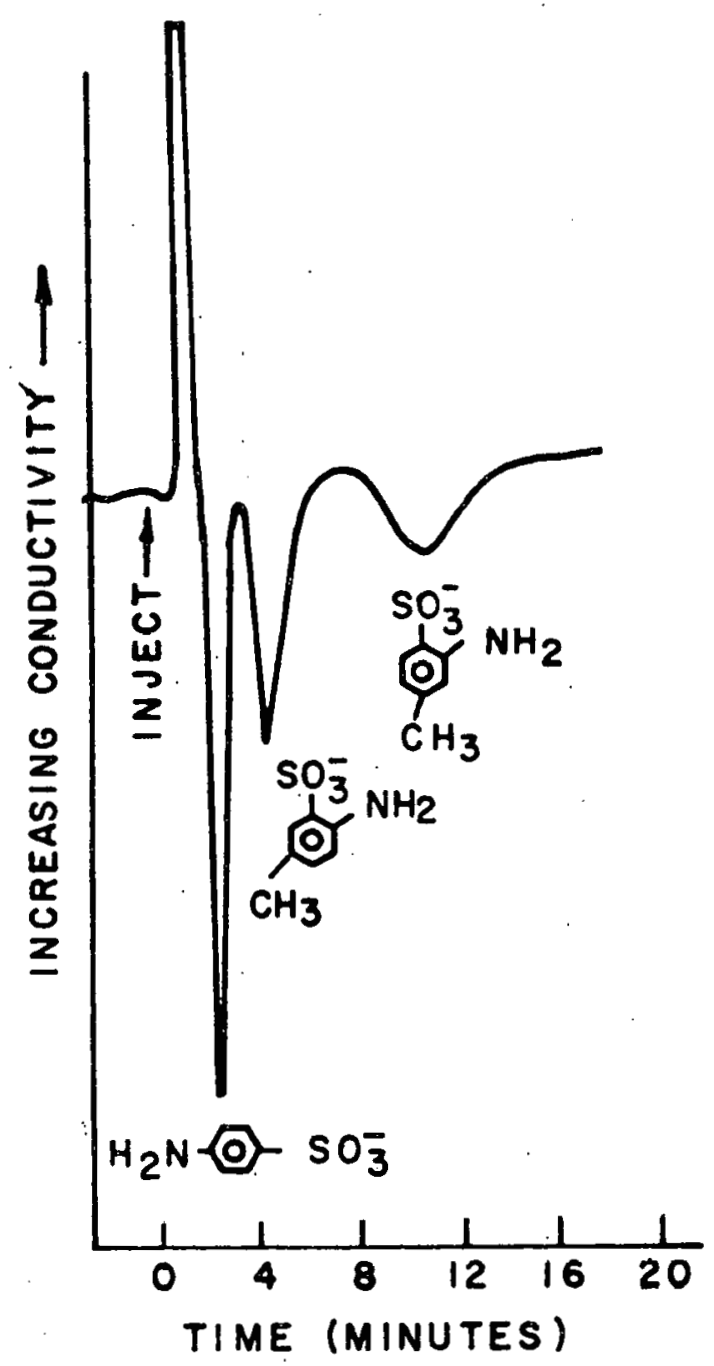

The eluent was $1.25 \times 10^{-4} \mathrm{M}$ trimesic acid at a $\mathrm{pH}$ of 6.0 . The anion-exchange column was $0.016 \mathrm{meq} / \mathrm{g}$ AN59-XA. The sample was $24.5 \mathrm{ppm}$ sulfanilic acid, $26.7 \mathrm{ppm} \mathrm{2,5-amino-}$ toluenesulfonic acid, and $26.3 \mathrm{ppm} 2,4$-aminotoluenesulfonic acid.

Figure 9. Separation of sulfanilic, 2,5-aminotoluenesulfonic, and 2,4-aminotoluenesulfonic acids using trimesic acid 


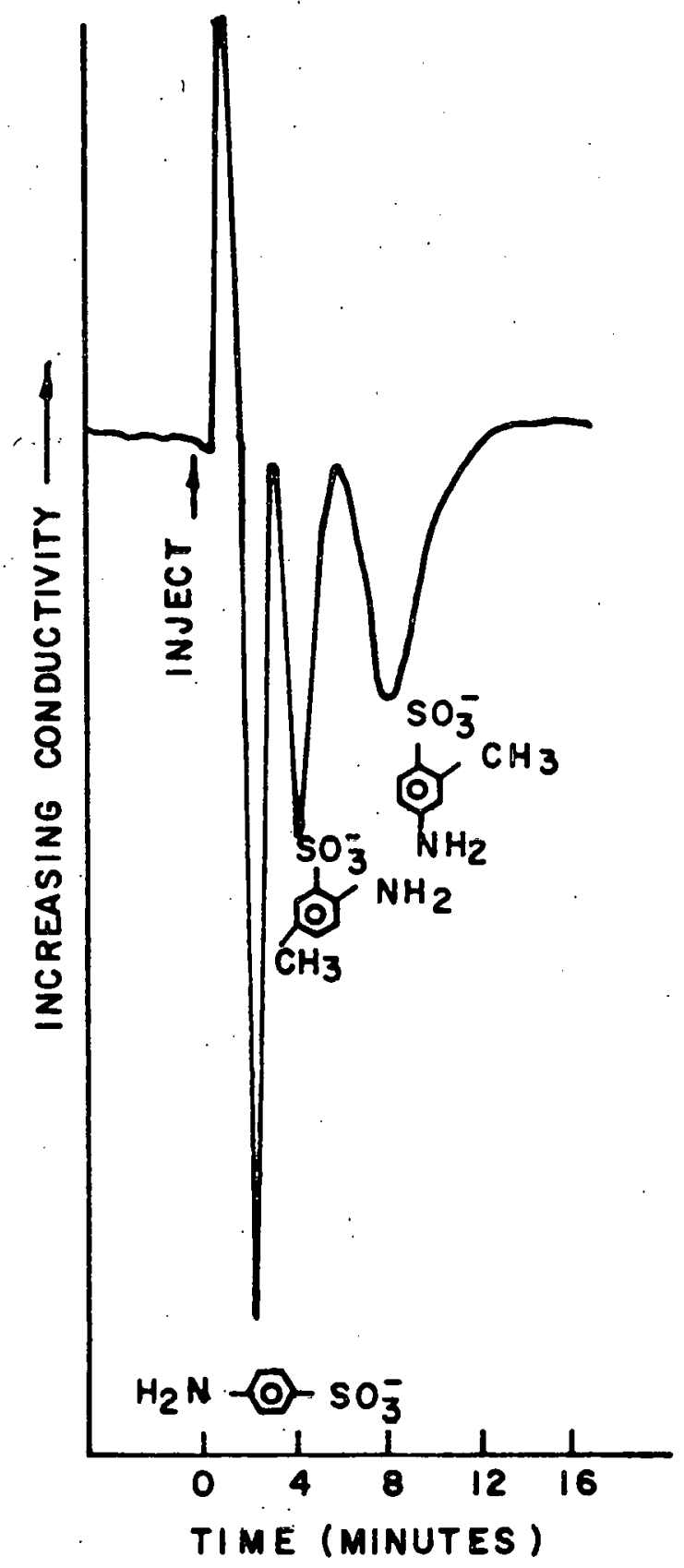

The eluent was $1.25 \times 10^{-4} \mathrm{M}$ trimesic acid at a $\mathrm{pH}$ of 6.0 . The anion-exchange column was $0.016 \mathrm{meq} / \mathrm{g}$ AN59-XA. The sample was $36.8 \mathrm{ppm}$ sulfanilic acid, $29.5 \mathrm{ppm} \mathrm{2,5-amino-}$ toluenesulfonic acid, and $60.6 \mathrm{ppm} \mathrm{4,2-aminotoluenesulfonic}$ acid.

Figure 10. Separation of sulfanilic, 2,5-aminotoluenesulfonic, and 4,2-aminotoluenesulfonic acids using trimesic acid 


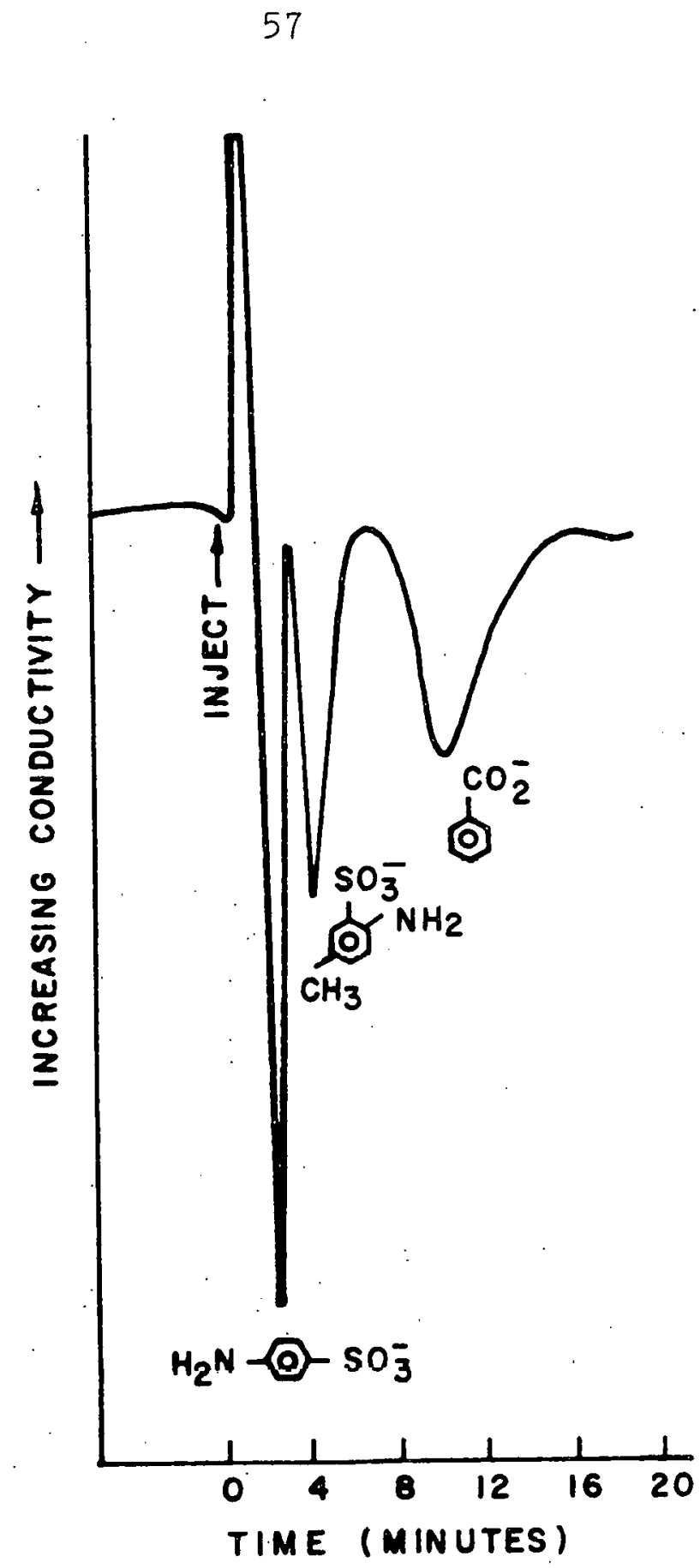

The eluent was $1.25 \times 10^{-4} \mathrm{M}$ trimesic acid at a $\mathrm{pH}$ of 6.0 . The anion-exchange column was $0.016 \mathrm{meq} / \mathrm{g}$ AN59-XA. The sample was $36.8 \mathrm{ppm}$ sulfanilic acid, $39.5 \mathrm{ppm} 2,5$-aminotoluenesulfonic acid, and $80.0 \mathrm{ppm}$ benzolc acid.

Figure 11. Separation of sulfanilic, 2,5-aminotoluenesulfonic, and benzoic acids using trimesic acid 


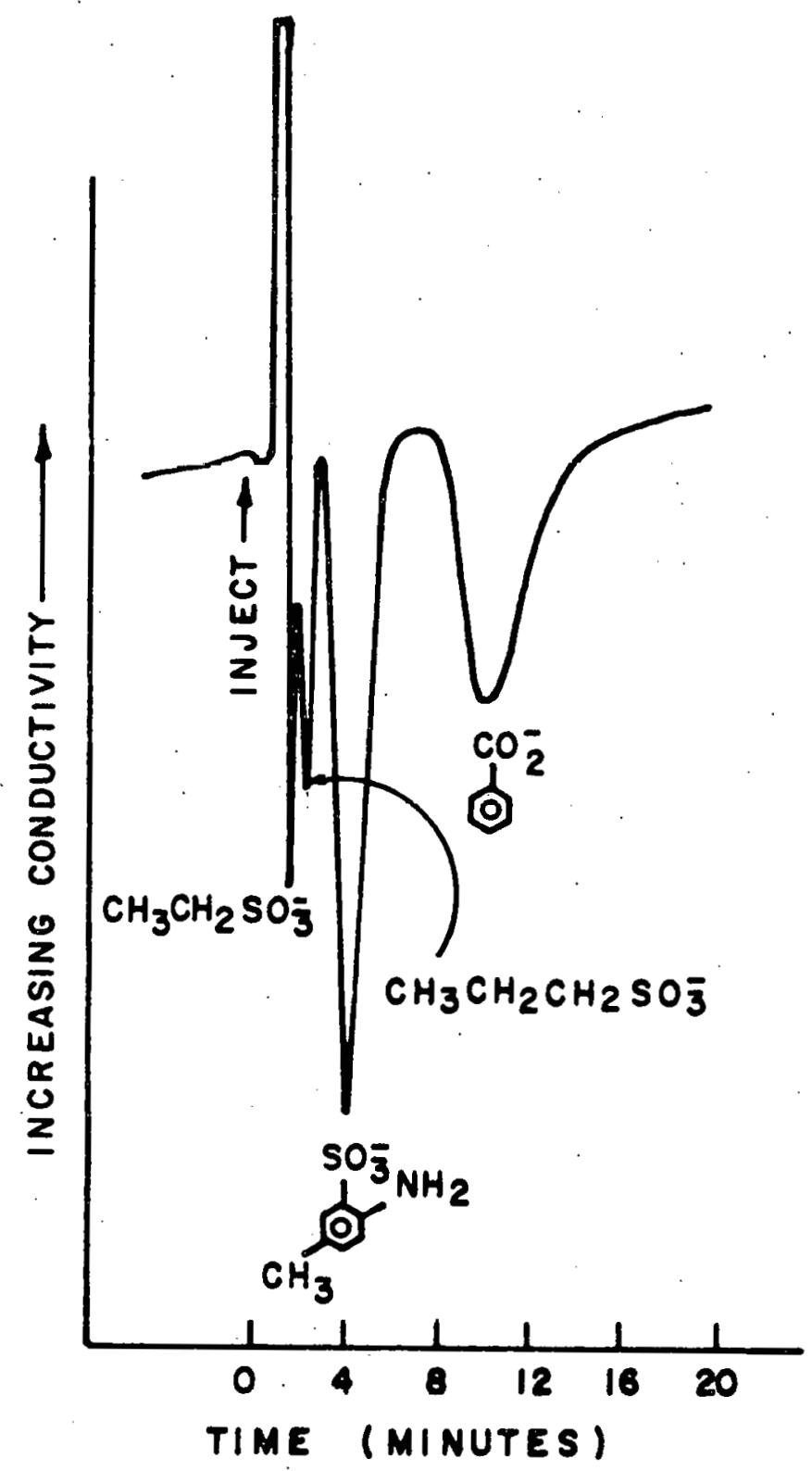

The eluent was $1.25 \times 10^{-4} \mathrm{M}$ trimesic acid at a $\mathrm{pH}$ of 6.0 . The anion-exchange column was $0.016 \mathrm{meq} / \mathrm{g}$ AN59-XA. The sample was $9.9 \mathrm{ppm}$ ethanesulfonic acid, $11.3 \mathrm{ppm}$ propanesulfonic acid, $59.2 \mathrm{ppm} 2,5$-aminotoluenesulfonic acid, and $80.0 \mathrm{ppm}$ benzoic acid.

Figure 12. Separation of ethanesulfonic, propanesulfonic, 2,5-aminotoluenesulfonic and benzoic acids using trimesic acid 


\section{CONCLUSIONS}

Choosing an Eluent

Of all the potential eluents surveyed, only the carboxylic acids and the nitrophenols are recommended as eluents for anion chromatography. This still leaves a dozen potential eluents to choose from when planning a separation. In order to determine which eluent to use for a particular sample, the characteristics of a good separation must be considered, The requirements for an anlytical separation include good resolution of the sample components, a reasonable analysis time, usually 20 minutes or less, and a sensitivity that is high enough to determine the species of interest without extensive sample manipulation. All these factors are controlled by the concentration of the eluent and the particular organic acid chosen as the eluent in nonsuppressed, anion-exchange chromatography.

The concentration of the eluent used in an anionexchange separation should be in the range of $5 \times 10^{-5}$ to $1 \times 10^{-3} \mathrm{M}$. The upper limit is a result of using a conductivity detector. When the eluent has a concentration above this limit, it produces a large background conductance and this reduces the sensitivity of the system. Eluents which are more dilute than $5 \times 10^{-5} \mathrm{M}$ give broad asymmetric peaks for a number of anions. If a good separation of the 
sample anions cannot be performed in this concentration range, another eluent should be used.

As a general rule, the eluent should have the same charge as that of the sample for inorganic anions and should have a higher charge than that of the sample for organic acid samples. The strongest eluent that gives a reasonable separation of the ions of interest should be used. It has been shown that the addition of an electron-withdrawing group or the geometric arrangement of the carboxylic acid groups affects the eluent's strength and these trends can be useful in choosing the best eluent. Choosing the stronger eluent allows a lower concentration of the eluent to be used which lowers the background and improves the sensitivity.. A stronger eluent also produces sharper sample peaks which further improves the sensitivity and creates the possibility of resolving more anions in a fixed amount of time.

As an aid in picking the correct eluent for a particular separation, a] of the recommended eluents are listed below in order of their decreasing strength as eluents: trimesic > citric > isophthalic > phthalic > terephthalic $\simeq$ o-nitrophenol >m-nitrophenol $>$ p-nitrobenzoic $\simeq$ p-nitrophenol $\simeq$ m-nitrobenzoic > benzoic > o-nitrobenzoic. 
Eluents for Typical Separations

Separation of halide ions

If the three most common halide ions $\left(\mathrm{F}^{-}, \mathrm{Cl}^{-}, \mathrm{Br}^{-}\right)$are to be determined in a single sample, the only eluent which has sufficient selectivity for these fast, eluting anions is benzoic acid. If one or two of these anions must be separated from iodide or other monovalent anions with long retention times; then the meta or para isomer of nitrobenzoic acid should be used as the eluent. This speeds up the separation and improves the shape of the more strongly retained anions. The nitrophenols are not recommended for either of these separations because this group of eluents has very little selectivity for monovalent anions.

\section{Separation of chloride and sulfate}

Many industrial applications of anion-exchange chromatography require the determination of only chloride and sulfate because these are the major components of the water samples. The phthalic acids are recommended as eluents for these determinations. Under some experimental conditions, the chloride peak is not well resolved from the pseudo peak and this lack of resolution complicates the analysis. In these cases, either the ortho or meta isomer of nitrophenol should be tried as the eluent. 
Separation of multivalent inorganic anions

The most useful eluents for separations of sulfate, chromate and other strongly retained inorganic anions are the phthalic acids. These eluents have the selectivity needed for the separation of these ions and produce reasonably short analysis times when the eluent has a concentration of $2 \times 10^{-4} \mathrm{M}$ or greater. Trimesic and citric aclas are not recommended for this type of separation because these eluents are too strong to give good selectivity differences among inorganic anions.

Separation of small alkyl acids

The alkyl carboxylic and sulfonic acids are more strongly retained by the ion-exchange resin than are inorganic anions. This fact leads to the recommendation of the phthalic acid as eluents for the separation of the anions. Trimesic and citric acids may be considered if the prospective separation includes acids with more than one acid group per molecule. Although o-nitrophenol is strong enough to be used for these separations, it does not have the selectivity required to make it a useful eluent for these samples.

Separation of aromatic acids

The best eluent for aromatic carboxylic and sulfonic acid samples is trimesic acid. As shown previously, this 
eluent has a remarkable selectivity and good retention times for these types of samples. Citric acid should also be considered as a potential eluent for these samples because it may have different selectivities for the various aromatic acids. 
- H'UTURE WORK

The basic characteristics of aromatic acids as eluents for anion-exchange chromatography have been outlined. Further work in this area should be directed at applying this information to improving separations which have already been done and performing separations which could not previously have been accomplished, The separation of carboxylic and sulfonic acids with trimesic acid as the eluent seems to be an especially promising area. It should be possible to separate a number of these acids, both aromatic and aliphatic, which have never before been separated by ion-exchange methods.

Another area of interest is the eluent peak. One of the major problems of using eluents at low $\mathrm{pH}$ values is the appearance of this extra peak. A study in which the adsorption. of the acids used as eluents on XAD-I as a function of $\mathrm{pH}$ would be useful. This study would determine exactly when an eluent peak would be expected to appear in a chromatogram. It would also be helpful in identifying compounds which are not highly adsorbed on XAD-1 and could lead to increasing the range of $\mathrm{pH}$ values where the eluent peak does not occur. This would simplify some of the separations which must be performed at low $\mathrm{pH}$ values. 


\section{REFERENCES}

1. Small, H.; Stevens, T. S.: Bauman, W. C. Anal. Chem. $1975,17,1801$.

2. Pohl, C. A.; Johnson. E. L. J. Chromatogr. Sci. 1980, 18,442 .

3. Gjerde, D. T.; Fritz J.S.; Schmuckler, G. J. Chromatogr. 1979; 186, 509.

4. Goldstein, S.; Schmuckler, G. Ion Exch. Membr. 1973, I, 135 .

5. Gjerde, D. T.; Fritz, J.S. J. Chromatogr. 1979, 176, 199.

6. Gjerde, D. T.; Schmuckler, G.; Fritz, J. S. J. Chromatogr. 1980, 187, 35 .

7. Fritz, J. S.; Gjerde, D. T.; Becker, R. M. Anal. Chem. $1980,52,1519$.

8. Charton, M. Prog. Phys. Org. Chem. 1971, 8, 235.

9. "Amberlite XAD macroreticular Adsorbents"; Rohm and Haas Co.: Philadelphia, 1970; Chapter 2.

10. Diehl, H. "Quantitative Analysis", 2nd ed.; Oakland Street Science Press: Ames, IA, 1974; Chapter 10.

11. Kortüm, G.; Vogel, W.; Andrussow, K. "Dissociation Constants of Organic Acids in Aqueous Solution", Ist ed.; Butterworths: London, 1961; Chapter 4.

12. Albert, A.; Serjeant, E. P. "Ionjzation Constants of Acids \& Bases"; John Wiley \& Sons: New York, 1962; Chapter 8 . 


\section{APPENDIX}

The lowest $\mathrm{pH}$ where ali of the eluent becomes ionized was calculated for each eluent to ensure that it was totally ionized during the chromatographic trials and to allow meaningful comparisons of eluent strength to be made. For eluents with one replaceabie hydrogen. this is analogous to titrating the eluent to its equivalence point with a strong base. The equations used to calculate the pH are derived in Quantitative Analysis [10] and are presented below:

$$
\begin{aligned}
& \mathrm{HA} \longrightarrow \mathrm{H}^{+}+\mathrm{A}^{-} \\
& \mathrm{HA}=\text { the eluent as an acid } \\
& \mathrm{A}^{-}=\text {the eluent as an anion } \\
& {\left[\mathrm{H}^{+}\right]=\sqrt{\frac{\mathrm{K}_{\mathrm{w}} \mathrm{K}_{\mathrm{a}}}{\mathrm{C}_{\mathrm{A}^{-}}}}} \\
& K_{W}=\text { the dissociation constant } \\
& \text { of water }=10^{-14} \\
& \dot{p} \mathrm{H}=-\log \left[\mathrm{H}^{+}\right] \\
& \mathrm{K}_{\mathrm{a}}=\text { the acid dissociation } \\
& \text { constant } \\
& \mathrm{C}_{\mathrm{A}^{-}}=\text {concentration of } \mathrm{A}^{-} \text {in } \\
& \text { solution }
\end{aligned}
$$

For eluents with more than one replaceable hydrogen, the pH where $100 \%$ ionization occurs can be calculated by considering the eluent anjon $\left(A^{-}\right)$as a weak base. In this case, only the weak acid is in solution and the appropriate equations are as follows:

$$
\mathrm{A}^{-}+\mathrm{H}_{2} \mathrm{O} \longrightarrow \mathrm{HA}+\mathrm{OH}^{-}
$$




$$
\begin{aligned}
& \mathrm{K}_{\mathrm{b}}=\mathrm{K}_{\mathrm{w}}-\mathrm{K}_{\mathrm{a}} \quad \mathrm{K}_{\mathrm{b}}=\text { the base dissociation } \\
& \text { constant }
\end{aligned}
$$

$$
\left[\mathrm{H}^{+}\right]=\sqrt{\frac{\mathrm{K}_{\mathrm{W}}^{2}}{\mathrm{~K}_{\mathrm{b}}\left[\mathrm{A}^{-}\right]}}
$$

$$
\mathrm{pH}=-\log \left[\mathrm{H}^{+}\right]
$$

The structure and $\mathrm{pK}_{\mathrm{a}}$ of each eluent used in this study are presented in Table 1A. The equivalence point for each acid group in these molecules was calculated and is also shown in Table lA. 
Table IA. Structure, dissociation constant and equivalence point of the eluents

\begin{tabular}{|c|c|c|c|}
\hline Name of eluent & Structure & $\mathrm{pk}_{\mathrm{a}}^{11,12}$ & $\begin{array}{l}\text { Equivalen } \\
\text { point }\end{array}$ \\
\hline$r$ & & & \\
\hline Benzoic acid & & $\mathrm{pK}_{1}=4.21$ & 7.10 \\
\hline $\begin{array}{l}\text { o-Nitrobenzoic } \\
\text { acid }\end{array}$ & & $\mathrm{pK}_{1}=2.22$ & 6.11 \\
\hline $\begin{array}{l}\text { m-Nitrobenzoic } \\
\text { acid. }\end{array}$ & & $\mathrm{pK}_{1}=3.46$ & 6.73 \\
\hline $\begin{array}{l}\text { p-Nitrobenzoic } \\
\text { acid. }\end{array}$ & & $\mathrm{pK}_{1}=3.44$ & 6.73 \\
\hline
\end{tabular}

o-Phthaic acid

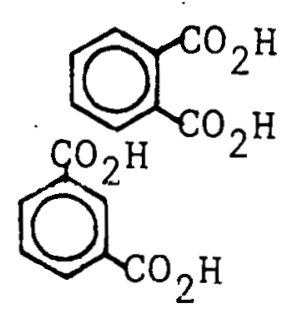

$$
\begin{array}{ll}
\mathrm{pK}_{1}=.2 .94 & 6.47 \\
\mathrm{pK}_{2}=5.42 & 7.71
\end{array}
$$

Isophthalic acia

$\begin{array}{ll}\mathrm{pK}_{1}=3.62 & 6.81 \\ \mathrm{pK}_{2}=4.60 & 7.30\end{array}$

Terephthalic acia

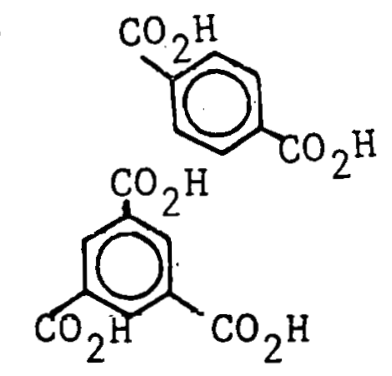

$$
\begin{array}{ll}
\mathrm{pK}_{1}=3.54 & 6.77 \\
\mathrm{pK}_{2}=4.46 & 7.23 \\
\mathrm{pK}_{1}=2.12 & 6.06 \\
\mathrm{pK}_{2}=3.89 & 6.95 \\
\mathrm{pK}_{3}=4.70 & 7.35
\end{array}
$$

Trimesic acid

The equivalence point was calculated using an eluent concentration of $1 \times 10^{-4} \mathrm{M}$ for each of the eluents. 
Table IA. (Continued)

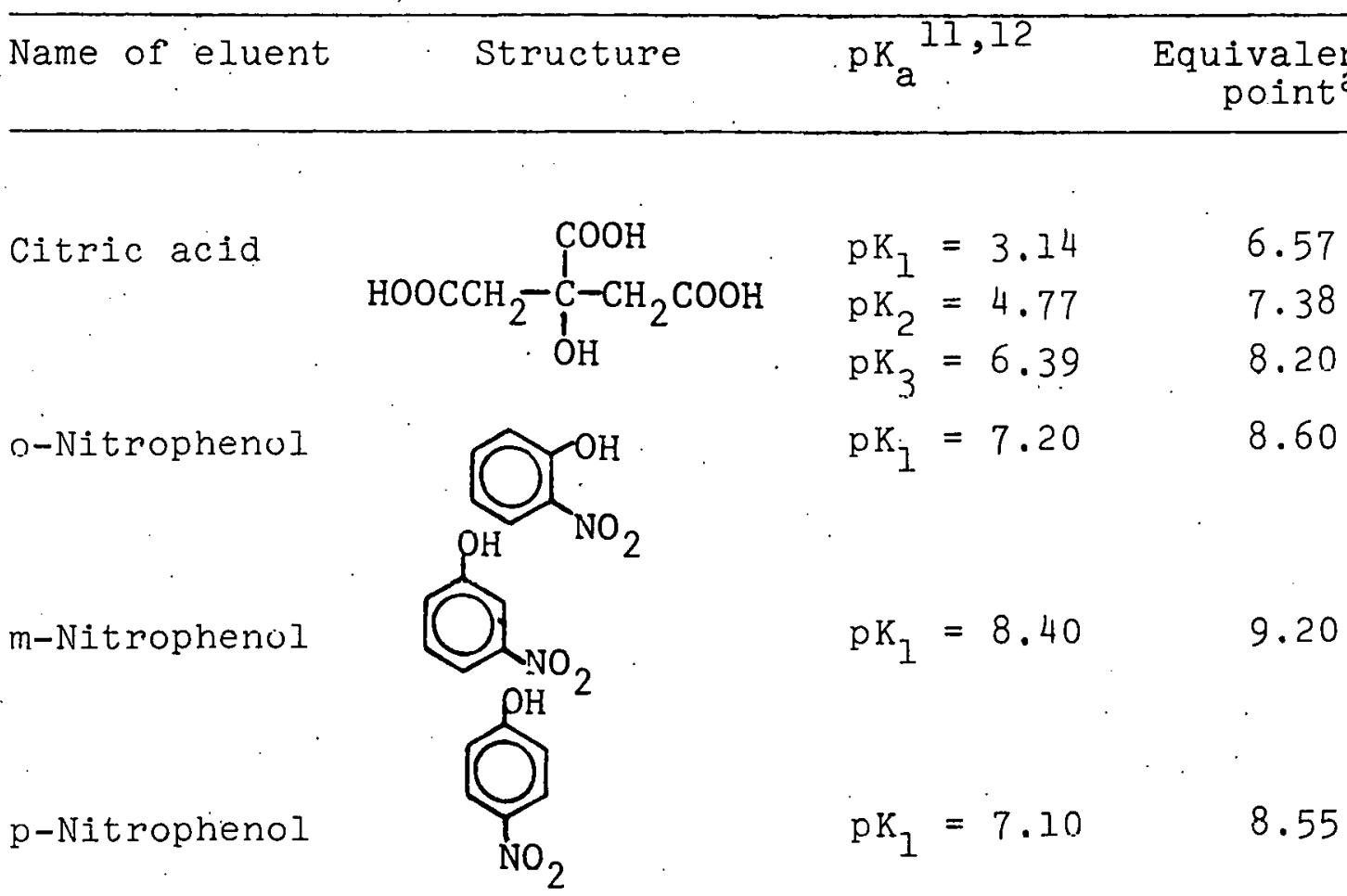

Benzenesulfonic acid<smiles>[SeH]c1ccccc1</smiles><smiles>Nc1ccc([134I])cc1</smiles>

\section{Sulfanilic} acid

Sulfobenzoic acid

Phenylphosphinic acid

Pheny lphosphonic acid<smiles>[2H]c1ccccc1</smiles>
$\mathrm{pK}_{1}=2.20$
6.10
$\mathrm{pK}_{2}=6.85$
8.43

$p K_{1}=3.12 \quad 6.56$

$\mathrm{pK}_{1}=0.31 \quad 5.15$

$\mathrm{pK}_{2}=3.80 \quad 6.60$

$\mathrm{pK}_{1}=2.10 \quad 6.05$

$\mathrm{pK}_{1}=2.55 \quad 6.28$

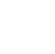

